\title{
Degradative behavior and toxicity of alkylated imidazoles
}

Sigvart Evjen ${ }^{\mathrm{a}}$, Ove Alexander Høgmoen Åstrand ${ }^{\mathrm{b}}$, Mona Gaarder ${ }^{\mathrm{c}}$, Ragnhild E. Paulsen ${ }^{\mathrm{c}}$, Anne Fiksdahl $^{\mathrm{a}}$, Hanna K. Knuutila ${ }^{\mathrm{d} *}$

a) Department of Chemistry, Norwegian University of Science and Technology (NTNU), 7491 Trondheim, Norway

b) Department of Pharmaceutical Chemistry, School of Pharmacy, University of Oslo, 0316, Oslo, Norway

c) Department of Pharmaceutical Biosciences, School of Pharmacy, University of Oslo, 0316, Oslo, Norway

d) Department of Chemical Engineering, Norwegian University of Science and Technology (NTNU), 7034 Trondheim, Norway

\section{Abstract}

The thermal and oxidative degradation behavior, as well as the corrosiveness of imidazole (Im), 2-methylimidazole (2MIm), 2-ethyl-4-methylimidazole (2E4MIm), 2,4,5-trimethylimidazole $(2,4,5 \mathrm{MIm})$ and 1,2,4,5-tetramethylimidazole $(1,2,4,5 \mathrm{MIm})$ were investigated in $\mathrm{CO}_{2}$ rich environment. The imidazoles demonstrated high thermal stability in all solutions; however, Im and 2MIm were corrosive. Polyalkylated imidazoles were less stable towards oxidation compared to Im. Rat cell (PC-12) toxicology screening of Im and 45 alkylated imidazoles showed reduced toxicity for polyalkylated imidazoles compared to $\mathrm{Im}$. Cell viability correlated negatively with cLogP predictions when $c \log P>3$. The high rate of oxidative degradation and formation of potentially carcinogenic degradation products will prevent the use of polyalkylated imidazoles in industrial processes directed towards $\mathrm{CO}_{2}$.

\section{Introduction}

Investigation of the degradation, corrosion and potential toxicity is an integral part of the assessment of new solvents for $\mathrm{CO}_{2}$ capture. In the chemical absorption process, $\mathrm{CO}_{2}$ is separated from flue gases by absorption into an alkaline absorbent at temperature around $40-60{ }^{\circ} \mathrm{C} . \mathrm{CO}_{2}$ is released from the absorbent as a pure gas by heating the solvent to $120{ }^{\circ} \mathrm{C}$ in a stripper. ${ }^{1}$ During the absorption process, the $\mathrm{CO}_{2}$ containing solvent is susceptible to degradation. Thermal degradation of the solvents occurs mainly in the stripper, as a result of high temperatures in the presence of $\mathrm{CO}_{2} .{ }^{2}{ }^{3}$ Whereas oxidative degradation is mostly described for absorber conditions, where $\mathrm{O}_{2}$ and other gas impurities are present in the flue gas. ${ }^{4}$ Solvent degradation results in solvent loss, formation of volatile compounds, foaming, fouling and corrosion. ${ }^{5}$ Degradation compounds typically have less favorable properties than the absorbent itself and are potentially more corrosive or toxic. ${ }^{6,7}$ Corrosion leads to dissolution of metal ions into the solvent, which in turn catalyzes further degradation of the absorbent. Higher rates of solvent degradation produce more waste, posing a potential health risk for people and the environment. Other solvent emissions occur by evaporation and aerosol emission from the absorption stack. ${ }^{8}$ Before large scale testing and implementation of technology, potential risks associated with new solvents need to be considered. Imidazoles, especially $N$-alkylimidazoles, have increasingly been proposed as 
potential co-solvents in $\mathrm{CO}_{2}$ capture applications. ${ }^{9-13}$ Among the interesting properties of alkylimidazoles is their high thermal stability in $\mathrm{CO}_{2}$ containing solutions. ${ }^{14}$ Polyalkylated imidazole based solvents enhance the $\mathrm{CO}_{2}$ absorption capacity of aqueous amines. ${ }^{10,15,16}$ In aqueous solution, polyalkylated imidazoles have absorption capacities comparable to traditional amines. ${ }^{15}$ Systems containing 2,4,5-trimethylimidazole $(2,4,5 \mathrm{MIm})$ possess high $\mathrm{CO}_{2}$ capacity at absorber conditions and are readily stripped at low temperatures, $80-90{ }^{\circ} \mathrm{C}$. ${ }^{15}$ As a surplus to high absorption capacity the amino-functionalized imidazoles have a high $\mathrm{CO}_{2}$ absorption rate. ${ }^{17,}{ }^{18}$ The $\mathrm{CO}_{2}$ capacity of amino-functionalized imidazoles is increased with additional alkyl substituents on the imidazole. ${ }^{18}$ In water lean solvents, alkyl imidazoles improve $\mathrm{CO}_{2}$ mass transfer rate coefficients compared to $\mathrm{N}$-methyl-2-pyrrolidone, dimethylsulfoxide, ethylene glycol and sulfolane. ${ }^{19}$ Non-aqueous $N$-alkylimidazoles have comparable physical $\mathrm{CO}_{2}$ solubility to ionic liquids, which have extensively been studied as $\mathrm{CO}_{2}$ solvents, ${ }^{20,21}$ but an order of magnitude lower viscosity. ${ }^{10}$ Thus, arguments could be made for exchanging ionic liquids with alkylimidazoles both in aqueous and non-aqueous systems. Imidazoles are often used as precursors for ionic liquids, and their use would reduce the number of synthetic steps towards the absorbent. Although there are a large number of studies on degradation ${ }^{22-24}$ and toxicity ${ }^{25-27}$ of imidazolium ionic liquids, such studies are severely limited for alkylimidazoles. A brief investigation into the degradation of imidazole ( $\mathrm{Im})$ in $\mathrm{CO}_{2}$ rich environment showed little degradation, but substantial corrosion at 5 $\mathrm{M}$ concentration. ${ }^{28}$ In the same study, lower concentration $(2.5 \mathrm{M})$ of $\mathrm{Im}$ was found to give depositions instead of corrosion. ${ }^{28}$ Several studies of the potential dangers and toxicity of simple imidazoles have been performed. Most simple imidazoles are corrosive towards skin and irritants. The toxicity of imidazole is comparable to that of methanol. ${ }^{29}$ Of different methyl functionalized imidazoles, 4-methylimidazole is the strongest convulsing agent and most toxic, and is linked with certain cases of ruminant losses. ${ }^{30} 2$ - And 4-methylimidazoles have been found to be potential carcinogens. ${ }^{31,32}$ The toxicity of 1-alkylimidazoles increases as the alkyl chain is elongated. ${ }^{29}$ By combining the toxicity of the imidazoles with the identification of possible degradation products formed during industrial processes, it might be possible to foresee potential hazards associated with these new solvents.

The aim of this study was to investigate the feasibility of polyalkylated imidazole based processes, by assessing the stability and toxicity of these imidazoles. The corrosive nature as well as thermal and oxidative behavior of imidazole ( $\mathrm{Im}), 2$-methylimidazole (2MIm), 2-ethyl-4-methylimidazole (2E4MIm), 2,4,5-trimethylimidazole (2,4,5MIm) and 1,2,4,5-tetramethylimidazole (1,2,4,5MIm) were explored. The toxicity of a total of 46 imidazoles was screened by MTT assay. Finally, the degradation results were used to construct a list of expected degradation products from different polyalkylated imidazoles.

\section{Materials and Methods}

An overview of the tested compounds is presented in Supporting Information. Imidazole (Im), 2methylimidazole (2MIm), 4-methylimidazole (4MIm), 2-ethylimidazole (2EIm), 1,2dimethylimidazole (1,2MIm), 2-ethyl-4-methylimidazole (2E4MIm) were obtained from Merck, Germany. 1,2,4,5-Tetramethylimidazole (1,2,4,5MIm) was obtained from TCI Europe, Belgium. $\mathrm{CO}_{2}$ was supplied by AGA, Norway. Commercial compounds were used without further purification. 2,4,5-Trimethylimidazole $(2,4,5 \mathrm{MIm})$ and other polyalkylated imidazoles were 
prepared as detailed in another work. ${ }^{33}$ The structures of the studied imidazoles with corresponding $\mathrm{p} K_{\mathrm{a}}$ values are given in Figure 1. Im, 2-MeIm, 2E4MIm, 2,4,5MIm and 1,2,4,5MIm were chosen for the degradation studies based on commercial availability, aqueous solubility and the varying degree of substitution of the imidazole ring.

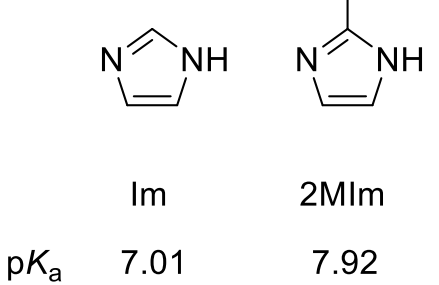

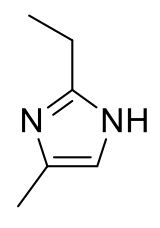

2E4MIm

8.38

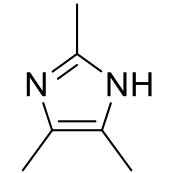

$2,4,5 \mathrm{MIm}$

8.90

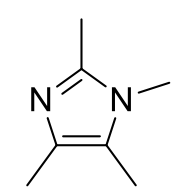

$1,2,4,5 \mathrm{Mlm}$

9.05

Figure 1: Imidazoles investigated in the degradation study with corresponding $\mathrm{p} K_{\mathrm{a}}$ values. ${ }^{6}$

Solutions containing $30 \mathrm{wt} \%$ imidazole were prepared with deionized water. The solutions were loaded with $\mathrm{CO}_{2}$ to a loading of mole $\mathrm{CO}_{2} /$ mole imidazole (Im and 2MIm) or 0.4 mole $\mathrm{CO}_{2} / \mathrm{mole}$ imidazole (2MIm, 2E4MIm, 2,4,5MIm and 1,2,4,5MIm) gravimetrically. A leaner $\mathrm{CO}_{2}$ loading was used for $\mathrm{Im}$, due to lower $\mathrm{CO}_{2}$ absorption capacity. Nine grams of each solution was added to eight cylinders ( 316 stainless steel, $3 \mathrm{~cm}$ diameter, $10 \mathrm{~cm}$ length) closed with Swagelok® end caps. All of the cylinders were new. The cylinders were kept at $135^{\circ} \mathrm{C}$ to accelerate thermal effects, ${ }^{34}$ and two cylinders for each solution were collected for analysis after 1, 3, 5 and 7 weeks. The experimental temperature is higher than the conventional industrial temperature for $\mathrm{CO}_{2}$ regeneration, to reduce length of the experiment. The cylinders were weighed at the start of the experiment and before analysis to detect leaks. A mass loss of $>5 \%$ was considered a leak, and 9 out of 40 cylinders leaked. The concentration of $\mathrm{Fe}, \mathrm{Cr}, \mathrm{Ni}, \mathrm{Mo}$ and $\mathrm{Mn}$ ions in solutions was analyzed by ICP-MS to measure the corrosion tendency. ${ }^{35}$ The alkalinity of the solutions was determined by $\mathrm{H}_{2} \mathrm{SO}_{4}$ titration, and was used as a measure of remaining imidazole. ${ }^{34}$ Average deviation between non-leaked duplicated were less than 3\%, indicating good reproducibility.

A modified version of a previous set-up by Vevelstad et al. ${ }^{36}$ was used to investigate the oxidative degradation behavior of imidazoles and imidazole/piperazine blends (Figure 2). The solutions (30 $\mathrm{wt} \%, 200 \mathrm{~mL}$ ) were preloaded with $\mathrm{CO}_{2}$ to a loading of $0.2 \mathrm{~mole} \mathrm{CO}_{2} /$ mole imidazole for $\mathrm{Im}$ and 0.4 mole $\mathrm{CO}_{2} / \mathrm{mole}$ imidazole for the other four imidazoles), and introduced into an open batch reactor $(250 \mathrm{~mL})$ equipped with a condenser. Gas $\left(80 \mathrm{vol} \% \mathrm{O}_{2}\right.$ and $\left.20 \mathrm{vol} \% \mathrm{CO}_{2}\right)$ was initially passed through deionized water for humidification before bubbling through the reactor. A gas mixture compromised of $\mathrm{CO}_{2}$ and $\mathrm{O}_{2}$ was used because $\mathrm{CO}_{2}$ has been shown to contribute to the degradation of alkaline compounds. ${ }^{4} \mathrm{~A}$ relatively high $\mathrm{CO}_{2}$ content in the gas compared to previous studies was used because imidazoles absorb $\mathrm{CO}_{2}$ as tertiary amines, absorbing $\mathrm{CO}_{2}$ by acting as a proton acceptor to form bicarbonate. ${ }^{15}$ The $\mathrm{CO}_{2}$ loadings of the solutions dropped during the experiment because of the formation of more acidic degradation products. Gas composition and flow rate $(60 \mathrm{~mL} / \mathrm{min})$ were controlled by Alicat mass flow controllers. The temperature of the experiments was maintained at $60{ }^{\circ} \mathrm{C}$ by a water bath. 


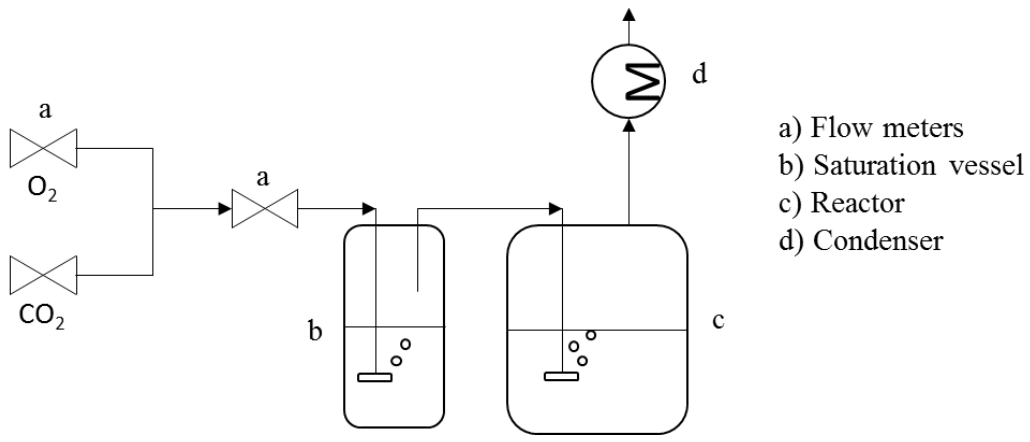

Figure 2: Schematics of oxidative degradation setup.

To accelerate the degradation, $0.5 \mathrm{mM}$ of $\mathrm{FeSO}_{4}$ was added to all experiments. ${ }^{37}$ The experimental time was 21 days, and samples were taken for amine analysis after 3, 7, 10, 14, 17 days and at the end of all experiments. Samples from the end of the experiment were analyzed by LC-HRMS and NMR to elucidate the structures of the main degradation products. NMR experiments were performed directly on the degraded aqueous sample, and used to determine the concentration of the compounds present in the degraded solutions. A capillary containing 2\% TMSP (3(trimethylsilyl)propionic-2,2,3,3-d4 acid sodium salt) in $\mathrm{D}_{2} \mathrm{O}$ was used as locking agent and NMR chemical shift reference. Water suppression was performed by NOESY experiment. Degradation products were confirmed by repeating the NMR experiments with commercial standards.

The rat pheochromocytoma cell line PC12 was grown in DMEM supplemented with 10\% FBS, $5 \%$ horse serum, sodium pyruvate $(1 \mathrm{mM})$ and $100 \mathrm{IU} / \mathrm{ml}$ penicillin $+100 \mu \mathrm{g} / \mathrm{ml}$ streptomycin, diluted to a concentration of $3.5 \times 10^{4}$ cells $/ \mathrm{ml}$ and plated $100 \mu \mathrm{l} /$ well in a $96-w e l l$, transparent, flatbottom cell culture plate (Nunc). Cells were incubated for $24 \mathrm{~h}$ at $37{ }^{\circ} \mathrm{C}$ and $5 \% \mathrm{CO}_{2}$, followed by exposure to $100 \mu \mathrm{M}$ imidazole toxicants (dissolved in ethanol to stock concentrations of $100 \mathrm{mM}$ ) in supplemented DMEM for yet $24 \mathrm{~h}$, before cell viability assessment with the MTT assay. MTT solution in PBS (5 mg/ml) was added to each well (1:10) of the 96 well plate, with the exception of the wells left for background subtraction. The plate was subsequently incubated at $37{ }^{\circ} \mathrm{C}$ and $5 \% \mathrm{CO}_{2}$ for $3 \mathrm{~h}$, before replacement of the MTT-solution with $100 \mu \mathrm{DMSO} /$ well for dissolution of the formazan salt. Absorbance was subsequently measured after $30 \mathrm{~min}$ at $570 \mathrm{~nm}$ in a CLARIOstar $^{\circledR}$ microplate reader (BMG Labtech, Ortenberg, BW, Germany), and the average blank value from wells containing cells without MTT, was subtracted.

\section{Results and Discussion}

\subsection{Thermal degradation in the presence of $\mathrm{CO}_{2}$}

The remaining alkalinity as a function of the duration of the thermal degradation experiments are displayed in Figures $3 \mathrm{a}$ and $3 \mathrm{~b}$. The observed degradation trend was $\operatorname{Im}(\alpha=0.2: 3.5 \mathrm{mmol} / \mathrm{kg} / \mathrm{h})$ $>2 \mathrm{MIm}(\alpha=0.2: 0.63 \mathrm{mmol} / \mathrm{kg} / \mathrm{h}, \alpha=0.4: 2.2 \mathrm{mmol} / \mathrm{kg} / \mathrm{h})>2 \mathrm{E} 4 \mathrm{MIm}(\alpha=0.4: 0.47 \mathrm{mmol} / \mathrm{kg} / \mathrm{h})$ $\approx 1,2,4,5 \mathrm{MIm}(\alpha=0.4: 0.42 \mathrm{mmol} / \mathrm{kg} / \mathrm{h})>2,4,5 \mathrm{MIm}(\alpha=0.4:$ no observed degradation $)$. The thermal stability appears to increase with $\mathrm{p} K_{\mathrm{a}}$, with the exception of $2,4,5 \mathrm{MIm}$ and $1,2,4,5 \mathrm{MIm}$, $\mathrm{p} K_{\mathrm{a}}$ values are shown in Figure 1. Addition of a methyl in 1-position on the imidazole ring reduces the imidazole's thermal stability. During the experiments, 2E4MIm and 1,2,4,5MIm appeared to degrade at the same rate. The degradation behavior of $2 \mathrm{MIm}$ depended heavily on the $\mathrm{CO}_{2}$ loading of the sample, as considerably more degradation occurred for the 0.4 mole $\mathrm{CO}_{2} /$ mole imidazole 
solutions compared to 0.2 mole $\mathrm{CO}_{2} /$ mole imidazole solutions. The observed effect of $\mathrm{CO}_{2}$ on degradation agrees well with previous reports. ${ }^{38,} 39$ No thermal degradation was observed for 2,4,5MIm. 2,4,5MIm forms a slurry with $\mathrm{CO}_{2},{ }^{15}$ and the 2,4,5-MIm samples remained slurries at the time of collection. In general, less degradation of the imidazoles was observed compared to amines studied in similar manner. ${ }^{34,40}$ Because imidazoles do not form carbamates, carbamate polymerization does not occur, contributing to the stability of the imidazoles. The thermal stability of alkylimidazoles with longer chain lengths are expected to be comparable to the imidazoles studied here.

Imidazoles can be synthesized by ring closing from corresponding diones, carbonyls and amines. This reaction is reversible, and under industrial operations, the imidazole might revert to its precursors. In the thermal degradation experiments, an equilibrium will be obtained between imidazole and starting materials (Scheme 1). Normally, the equilibrium is shifted towards imidazole, but in some cases, the precursors are liable. Formaldehyde and ammonia can polymerize in alkaline solution, ${ }^{41}$ and glyoxal degrades to oxalic and formic acid. The constant degradation of Im could be explained by degradation of glyoxal or formaldehyde. Because the cylinders were closed, formed ammonia, amine or aldehyde were not lost through evaporation, and in the case of non-degradative adducts, equilibrium was maintained throughout the degradation. The concentrations of formaldehyde and ammonia were not measured after the degradation experiments. As imidazole can potentially degrade to formaldehyde, a known carcinogen, the use of imidazole or other $2-\mathrm{H}$ imidazoles in processes should be carefully evaluated.

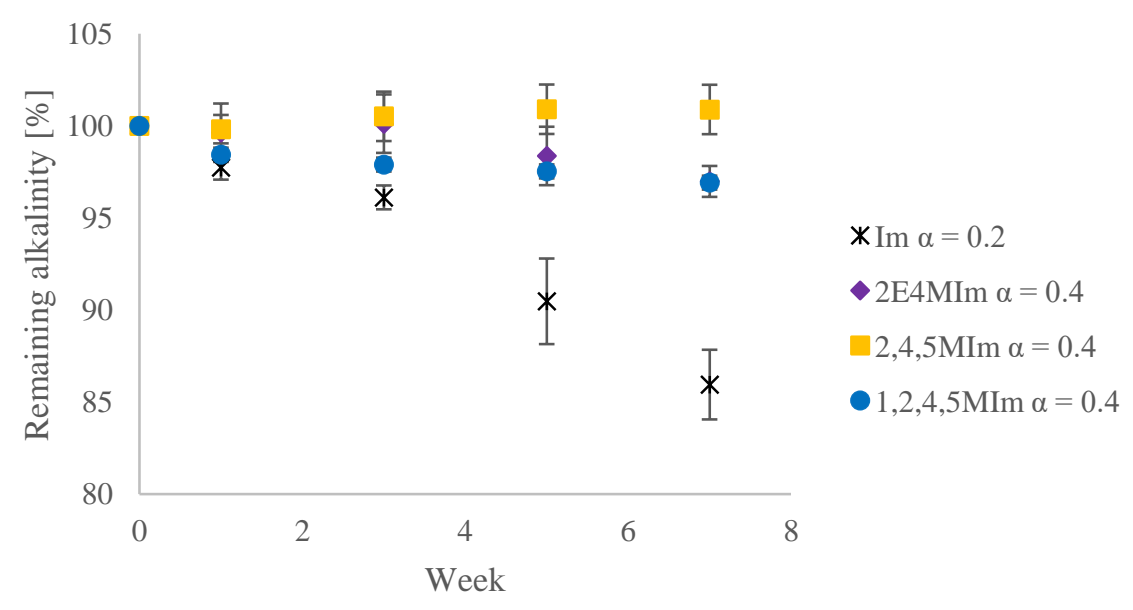

Figure 3a: Thermal degradation; \% remaining alkalinity as a function of time for Im, 2E4MIm 2,4,5MIm and 1,2,4,5MIm in aqueous solution with $\mathrm{CO}_{2}$ loading, $\alpha, 0.2$ and 0.4 mole $\mathrm{CO}_{2} / \mathrm{mole}$ imidazole at $135^{\circ} \mathrm{C}$. 


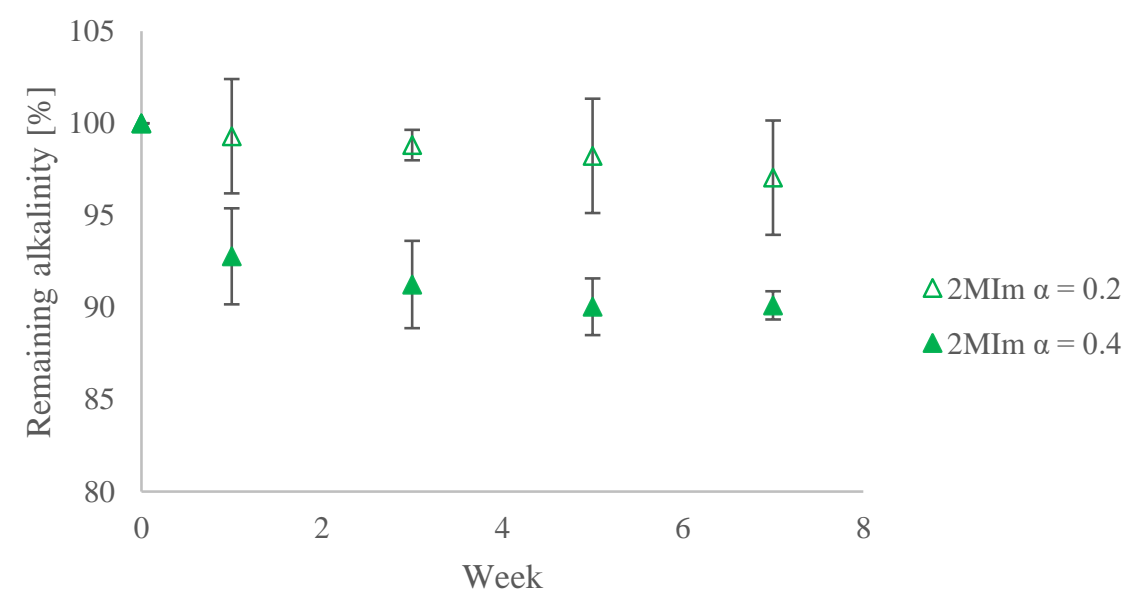

Figure 3b: Thermal degradation; of $2 \mathrm{MIm}$ in aqueous solution at $135{ }^{\circ} \mathrm{C}$ with $\mathrm{CO}_{2}$ loading, $\alpha, 0.2$ and 0.4 mole $\mathrm{CO}_{2} /$ mole imidazole; measured as $\%$ remaining alkalinity as a function of time.

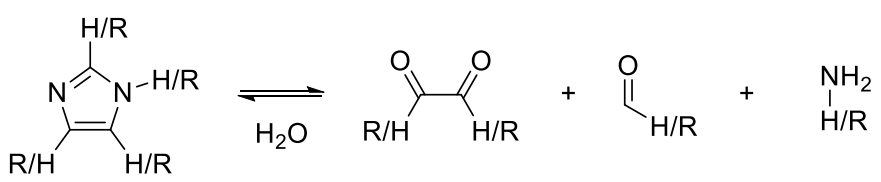

Scheme 1: Reversible degradation pathway by ring-opening.

\subsection{Corrosion}

The concentrations of dissolved $\mathrm{Cr}, \mathrm{Fe}, \mathrm{Ni}, \mathrm{Mn}$ and Mo ions in the degraded samples at the end of thermal degradation experiments (7 weeks) are shown in Figure 4. The metal ion concentration in the different solutions are given in Table 1 . The composition of 316 stainless steel is Fe, $\mathrm{C}<0.08 \%$, Cr 16-18.5\%, Ni 10-14\%, Mo 2-3\%, Mn $<2 \%$, Si $<1 \%, \mathrm{P}<0.045 \%$, S < 0.03\%. The Im sample contained the highest concentrations of $\mathrm{Cr}, \mathrm{Mn}$ and $\mathrm{Mo}$, whereas the highest $\mathrm{Fe}$ and $\mathrm{Ni}$ concentrations were observed in 2MIm solutions (Figure 4). Measured Fe included all forms of Fe. Increased corrosion took place in solutions containing higher $\mathrm{CO}_{2}$ loadings, in accordance with previous findings. ${ }^{34,39,42}$ The Fe concentrations in $2 \mathrm{MIm}$ were three times higher when the $\mathrm{CO}_{2}$ concentration was increased from 0.2 to 0.4 mole $\mathrm{CO}_{2} /$ mole amine. Imidazole solutions containing 0.4 mole $\mathrm{CO}_{2} /$ mole amine had reduced corrosiveness in the order $2 \mathrm{MIm}>2 \mathrm{E} 4 \mathrm{MIm}>2,4,5 \mathrm{MIm} \approx 1,2,4,5 \mathrm{MIm}$, in accordance with $\mathrm{p} K_{\mathrm{a} .}{ }^{15} 2,4,5 \mathrm{MIm}$ was more corrosive than 1,2,4,5MIm for $\mathrm{Cr}$, Fe and $\mathrm{Ni}$, and vice versa for $\mathrm{Mn}$ and $\mathrm{Mo}$. The amount of $\mathrm{Fe}$ dissolved in $2 \mathrm{MIm}(1.5 \mathrm{~g} / \mathrm{L})$ was 1000 times higher than in 1,2,4,5MIm $(1.2 \mathrm{mg} / \mathrm{L})$. The corrosion trend can be explained by the basicity of the alkylimidazoles. The more alkaline imidazoles adsorb more favorably on to the metal surface, acting as a corrosion inhibitor. ${ }^{43}$ This trend is clearly demonstrated in Figure 4. The observed corrosion for the $30 \mathrm{wt} \%$ imidazole solution was in accordance with previous reports. ${ }^{28}$

As mentioned in the introduction, the correlation between metal ion concentration in solutions and degradation have been demonstrated in previous studies. $\mathrm{Fe}^{2+}$ is considered one of the primary catalysts for degradation. ${ }^{37,} 44$ The degradation trend observed for the imidazoles 
$(\mathrm{Im}>2 \mathrm{MIm}>2 \mathrm{E} 4 \mathrm{MIm} \approx 2,4,5 \mathrm{MIm}>1,2,4,5 \mathrm{MIm}$, Figures $3 \mathrm{a}$ and $3 \mathrm{~b})$ were to an extent is in line with the metal ion concentration in the same solutions, with the exception of the higher $\mathrm{Fe}^{2+}$ concentrations in $2 \mathrm{MIm}$ solutions compared to Im. Thermal degradation of imidazole might therefore not be sensitive to $\mathrm{Fe}^{2+}$ concentration. The imidazoles expressed elevated corrosiveness towards Mo compared to tertiary alkanolamines. ${ }^{34} 1,2,4,5 \mathrm{MIm}$ was comparable to less aggressive amines regarding $\mathrm{Cr}, \mathrm{Fe}$ and $\mathrm{Ni}$ corrosion. ${ }^{34}$ Polyalkylated imidazoles with longer alkyl chains are expected to be better corrosion inhibitors than $2,4,5 \mathrm{MIm}$ or $1,2,4,5 \mathrm{MIm}$ because of lower aqueous solubility. ${ }^{43}$ The increased free energy of adsorption for these imidazoles would improve metal surface coverage. ${ }^{43}$ The improved corrosion inhibition may reduce the corrosiveness and degradation.

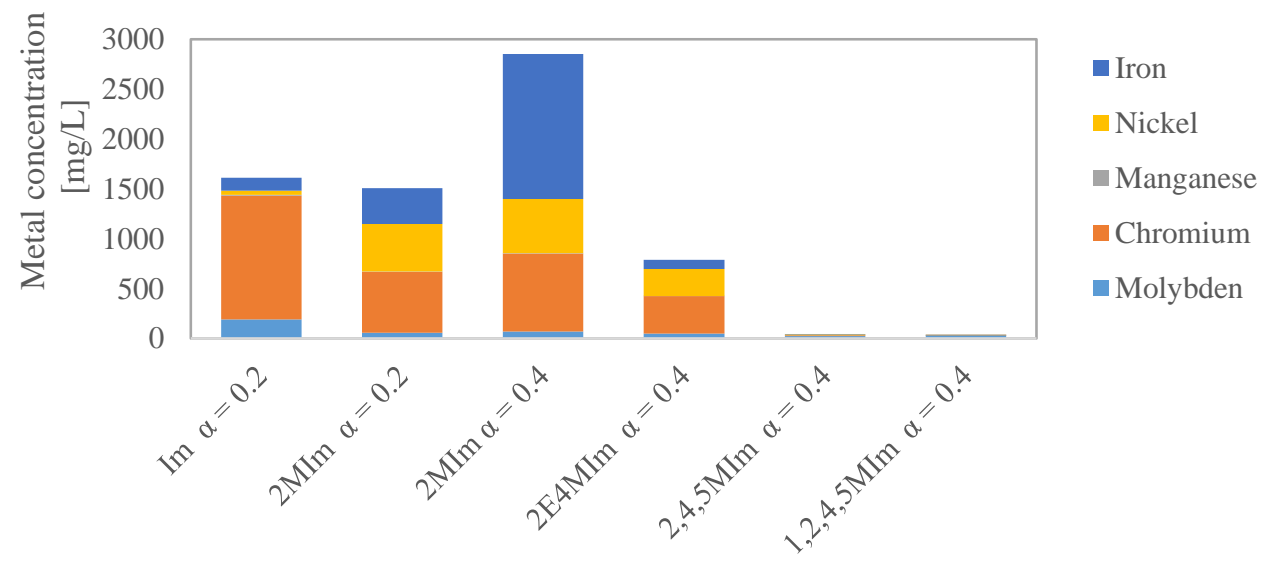

Figure 4: Corrosion studies; $\mathrm{Fe}, \mathrm{Ni}, \mathrm{Mn}, \mathrm{Cr}$ and $\mathrm{Mo}$ ion concentrations $(\mathrm{mg} / \mathrm{L})$ in $\mathrm{CO}_{2}$ loaded $\mathrm{Im}$, 2MIm, 2E4MIm, 2,4,5MIm and $1,2,4,5 \mathrm{MIm}$ solutions ( $\alpha=0.2$ or $0.4 \mathrm{~mole} \mathrm{CO}_{2} /$ mole imidazole) at the end of thermal degradation experiments ( 7 weeks). The individual concentrations and uncertainty in the analytical measurement of each metal are given in Table 1.

Table 1: Corrosion studies; $\mathrm{Fe}, \mathrm{Ni}, \mathrm{Mn}, \mathrm{Cr}$ and $\mathrm{Mo}$ ion concentration $(\mathrm{mg} / \mathrm{L})$ in $\mathrm{CO}_{2}$ loaded solutions, with uncertainties from ICP-MS measurement.

\begin{tabular}{ccccccc}
\hline Solution & Loading & \multicolumn{4}{c}{ Metal concentration [mg/L] } \\
& $\alpha$ & $\mathrm{Fe}$ & $\mathrm{Ni}$ & $\mathrm{Mn}$ & $\mathrm{Cr}$ & $\mathrm{Mo}$ \\
\hline Blank $^{\mathrm{a}}$ & - & $0.010 \pm 0.002$ & $0.013 \pm 0.001$ & $0.004 \pm 0.002$ & $0.001 \pm 0.001$ & $0.003 \pm 0.001$ \\
$\mathrm{Im}=$ & 0.2 & $129 \pm 1$ & $26 \pm 1$ & $7.6 \pm 0.2$ & $1220 \pm 30$ & $189 \pm 3$ \\
$2 \mathrm{MIm}$ & 0.2 & $367 \pm 9$ & $12.3 \pm 0.2$ & $2.25 \pm 0.04$ & $607 \pm 10$ & $58 \pm 2$ \\
2MIm & 0.4 & $1456 \pm 20$ & $13.9 \pm 0.1$ & $4.87 \pm 0.03$ & $778 \pm 20$ & $70 \pm 2$ \\
2E4MIm & 0.4 & $89 \pm 1$ & $6.9 \pm 0.1$ & $0.181 \pm 0.004$ & $376 \pm 6$ & $48 \pm 1$ \\
$2,4,5 \mathrm{MIm}$ & 0.4 & $2.7 \pm 0.3$ & $4.5 \pm 0.1$ & $0.0096 \pm 0.0005$ & $9.1 \pm 0.1$ & $22.4 \pm 0.7$ \\
$1,2,4,5 \mathrm{MIm}$ & 0.4 & $1.2 \pm 0.1$ & $4.71 \pm 0.05$ & $0.0160 \pm 0.0005$ & $1.59 \pm 0.03$ & $30.6 \pm 0.4$ \\
\hline
\end{tabular}

a) Deionized water used for both solution preparation and for dilution of samples run on ICP-MS.

\subsection{Oxidative degradation}

The remaining amount of (alkyl)imidazole in aqueous solution throughout the degradation experiments is depicted in Figure 5. Uncertainties were calculated from deviation between three repeated experiments using $2 \mathrm{MIm}$. A list of identified degradation products, including NMR peak assignments and concentrations, is given in Supporting Information. The oxidative degradation trend of the imidazoles was the opposite to that of the thermal degradation (Figures $3 \mathrm{a}$ and $3 \mathrm{~b}$ ), as 
additional alkyl substituents severely reduced the stability of the imidazoles. Unsubstituted imidazole was found to be resistant towards oxidation, in agreement with previous reports. ${ }^{28}$ The limited oxidation of $\mathrm{Im},<3 \%$, can partially be explained by the lower $\mathrm{CO}_{2}$ solubility in aqueous imidazole solutions. The thermally stable 2,4,5MIm experienced an amine loss of almost $70 \%$, whereas a loss close to $80 \%$ was observed for $1,2,4,5 \mathrm{MIm}$. The degradative trend suggests that electron rich imidazole are more prone to oxidize. Additional substituents increase the number of methyl/alkyl groups available for oxidation.

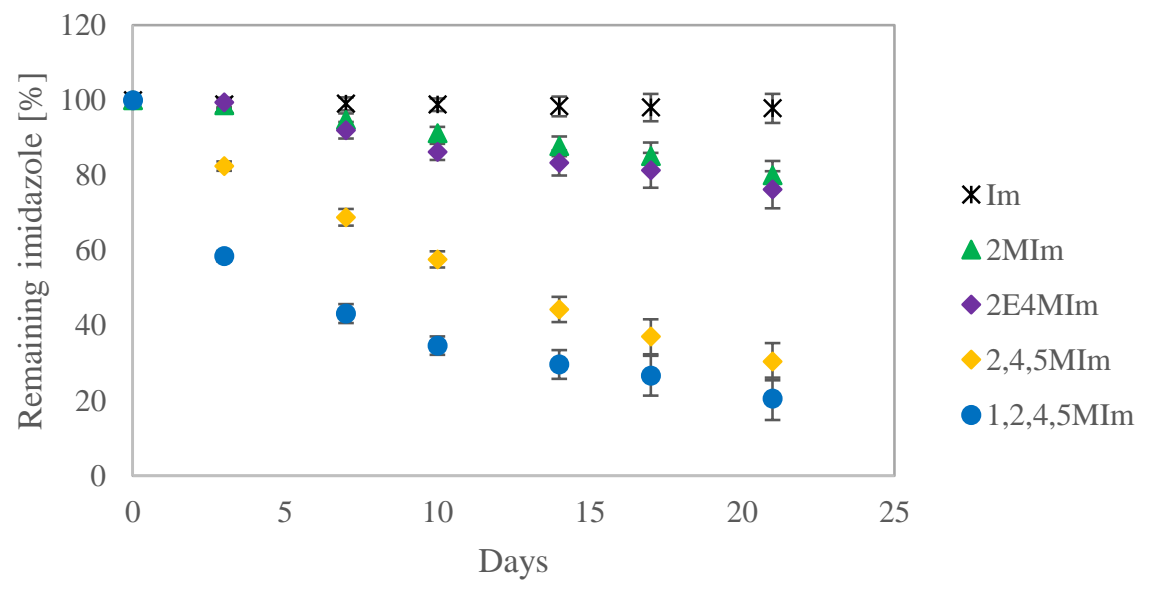

Figure 5: Oxidative degradation; measured as \% remaining (alkyl)imidazoles Im, 2MIm, 2E4MIm, $2,4,5 \mathrm{MIm}$ and $1,2,4,5 \mathrm{MIm}$ as a function of time ( $3 \mathrm{M}$ aqueous solution, $60{ }^{\circ} \mathrm{C}$, bubbling of $\mathrm{CO}_{2} / \mathrm{O}_{2}$ 20:80).

The final degradation products of the alkylated imidazoles were mainly acids or amides. An overview of the concentration of the most abundant acid and amide products are displayed in Figure 6. Proposed degradation pathways of the different imidazoles and corresponding degradation products are depicted in Schemes 2-4. The degradation of $2 \mathrm{MIm}$ is potentially initiated by an oxidation on the imidazole ring, forming a lactam. Because the ring aromaticity is lost, the ring is susceptible to ring opening, see Scheme 2. An intermediate corresponding to the imidazoline was identified by HRMS $\left(\mathrm{m} / \mathrm{z}=81.0452, \mathrm{M}+\mathrm{H}-\mathrm{H}_{2} \mathrm{O}\right)$. Based on the concentrations of the degradation products in solution, the ring opening is proposed to progress sequentially, by initial loss of $\mathrm{NH}_{3}$ by hydration, and either oxidative amine elimination (Route I) or amide hydrolysis (Route II). The formed glyoxalic acid Route (I) is oxidized to formic acid, $\mathrm{CO}_{2}$ and oxalic acid, while aminoacetic acid (Route II) affords formamide, formic acid and $\mathrm{CO}_{2}$. The concentrations of formamide and acetic acid were almost equal, supporting the proposed mechanism, and suggesting that oxidation (Route I) is favored for 2MIm. 2E4MIm is suggested to follow the same degradation pattern as $2 \mathrm{MIm}$, with initial oxidation of the imidazole ring (Scheme 3). 2-Oxopropanoic acid $(\mathrm{m} / \mathrm{z}=87.0084, \mathrm{M}-\mathrm{H})$ was detected in 2E4MIm HRMS samples. The total concentration of propanoic acid and propanamide in 2E4MIm solutions was close to the total concentration of acetic acid and acetamide, supporting the proposed degradation mechanism for 2MIm and 2E4MIm. HRMS (data) suggested that exocyclic oxidation of 2E4MIm occurs. NMR spectra displayed minor/minute aromatic signals of several aromatic compounds, but structures were not elucidated. 


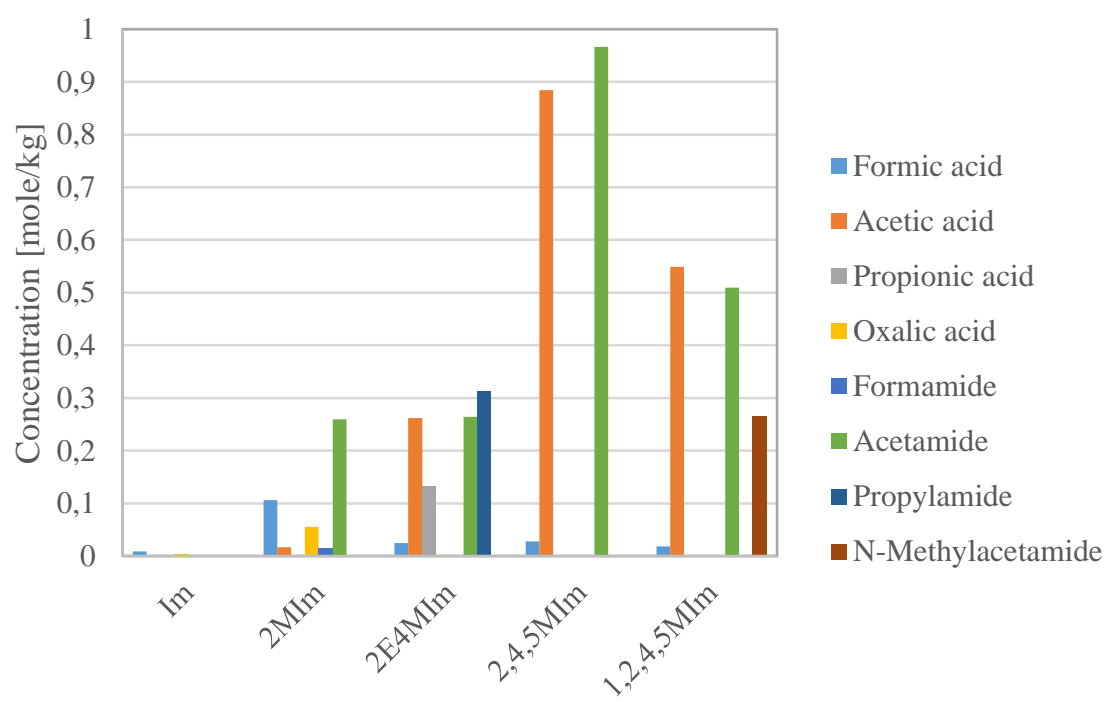

Figure 6: Oxidative degradation; concentration of acids and amides in Im, 2MIm, 2E4MIm, 2,4,5MIm and 1,2,4,5MIm solutions at the end of oxidation experiments (3 weeks).

Four degradation pathways are proposed for 2,4,5MIm (Scheme 4). 1,2,4,5MIm is expected to behave in similar fashion as $2,4,5 \mathrm{MIm}$. The major degradation products for both $2,4,5 \mathrm{MIm}$ and 1,2,4,5MIm were acetic acid and acetamide. As ring oxidation of 2,4,5MIm and 1,2,4,5MIm prevent lactam formation, an epoxide is a likely product from the first oxidation (Route III). The epoxide has been suggested to further oxidize to diol, and subsequent oxidation affords ring opening, Route IV. ${ }^{45}$ Route IV is expected to give an acetic acid/amide ratio of 2:1. Because the 2,4,5MIm solution contains more acetamide than acetic acid, a competing ring opening mechanism, Route V, potentially occurs. This alternative mechanism would afford an acid/amide ratio of 1:2, given that acetonitrile does not evaporate before oxidation. Acetonitrile was not observed in NMR. 2-H imidazole derivatives were detected for both 2,4,5MIm and 1,2,4,5MIm (Route VI). The 4(5)-alcohol derivative of 2,4,5MIm, an adduct according to Route VII, was identified in NMR and MS (m/z = 127.0867, M+H). Imidazole aldehydes $(\mathrm{m} / \mathrm{z}=127.0867, \mathrm{M}+\mathrm{H})$ and carboxylic acids $(\mathrm{m} / \mathrm{z}=139.0506, \mathrm{M}-\mathrm{H})$ were detected in HRMS. Aromatic degradation compounds formed by variable degree of exocyclic oxidation, were visible in NMR, but the high number of NMR signals made assignments difficult. More degradation compounds were observed for $1,2,4,5 \mathrm{MIm}$ than $2,4,5 \mathrm{MIm}$, due to oxidation of the nitrogen methyl. $N$-Methylacetamide was one of the major degradation products from 1,2,4,5MIm, supporting the proposed imidazole ring opening mechanism by Route IV. No traces of N-O oxidation products were observed in NMR for any of the imidazoles, suggesting that initial oxidation on nitrogen is not a degradation pathway for imidazoles in aqueous solution. Oxalic acid was not detectable in NMR for neither $2,4,5 \mathrm{MIm}$ nor $1,2,4,5 \mathrm{MIm}$.

The small amount of formic acid $(0.09 \mathrm{M})$ and oxalic acid $(0.04 \mathrm{M})$ formed in the degradation of Im, 0.1 M loss, appeared to correspond to all the degraded material. However, the degradation of Im was so low that the uncertainty in Im concentration was larger than the formic acid concentration. The nitrogen is expected to have been removed as ammonia. The concentration of 2MIm decreased by $0.7 \mathrm{M}$, and the combined concentration of degradation species shown in Figure 
6 was $0.45 \mathrm{M}$. Oxalic acid is expected to have been oxidized to $\mathrm{CO}_{2}$ and been flushed out by the gas bubbled through the system. The total imidazole loss of 2E4MIm was $0.64 \mathrm{M}$ and the concentration of the species was $1.0 \mathrm{M}$. A concentration loss as high as $1.89 \mathrm{M}$ was obtained for 2,4,5MIm during the experiment and about half of the degradation proceeded to acetic acid $(0.88$ $\mathrm{M})$ and acetamide $(0.97 \mathrm{M})$. Oxidation of 1,2,4,5MIm, $1.90 \mathrm{M}$ lost, produced a combined amount of $1.34 \mathrm{M}$ of small acids and amides, Figure 6 . From the NMR spectra of the degraded solutions, see Supporting Information, it appears that much of imidazole loss not accounted for in Figure 6 is degradation to partially oxidized imidazoles.

The substantial degradation observed in this study indicates that polyalkylated imidazoles are unsuited for applications where oxidative degradation is expected, without an appropriate oxidation inhibitor. Although not investigated in this work, the degradation of other imidazoles with longer alkyl chains or other functionalities are expected to follow similar oxidative pathways to the ones discussed herein.

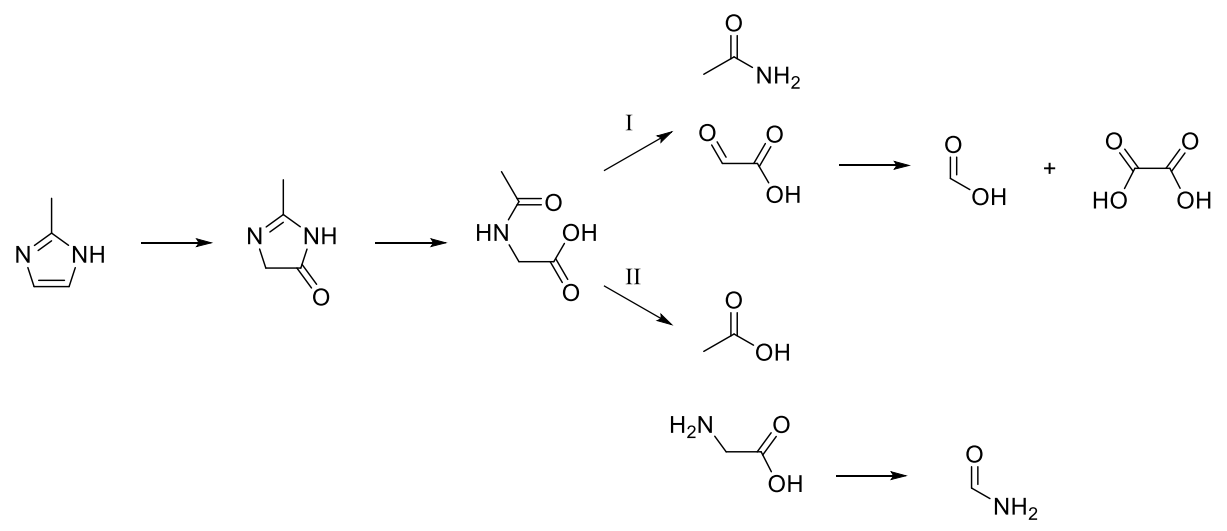

Scheme 2: Proposed oxidative degradation pathway for 2MIm.

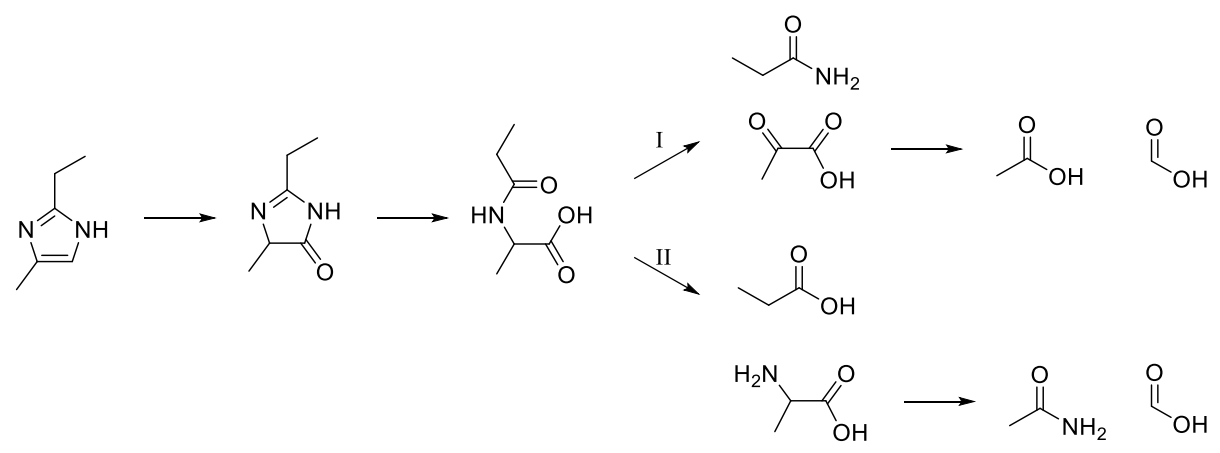

Scheme 3: Proposed oxidative degradation pathway for 2E4MIm. 


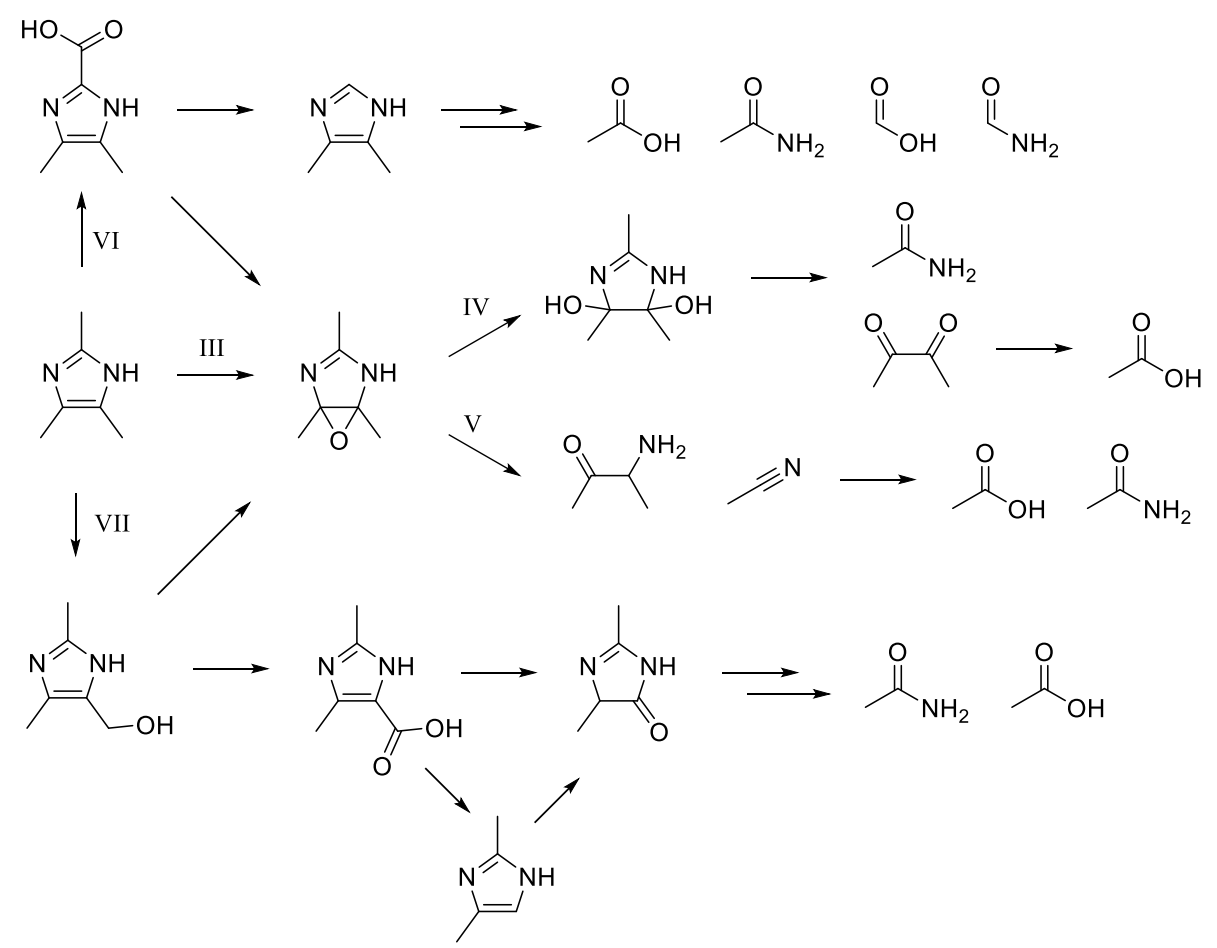

Scheme 4: Proposed oxidative degradation pathways for 2,4,5MIm.

\subsection{Toxicology screening of imidazoles and hazards of imidazole degradation products}

To consider the possible environmental and health risks associated with the use of polyalkylated imidazoles in $\mathrm{CO}_{2}$ capture, a large number of polyalkylated imidazoles were toxicologically screened by MTT analysis. The structures of the tested imidazoles with corresponding abbreviation are given in Figure S1 in Supporting Information. In addition, the known hazards reported for the degradation products of the studies imidazoles, Im, 2MIm, 2E4MIm, 2,4,5MIm and 1,2,4,5MIm are given in Table 2. Potential degradation products from the other alkylated imidazoles in Figure $\mathrm{S} 1$ are also included in Table 2. The results from the toxicological screening (Figure 7), where the viability of PC-12 cells is compared with a vehicle-exposed sample, show that most of the imidazoles exhibit low toxicity under the measurement conditions. The smallest imidazoles were the most toxic, and toxicity decreased with additional alkyl substituents. $N$-Methylation from $4,5 \mathrm{MIm}$ to $1,4,5 \mathrm{MIm}$ and from $2 \mathrm{MIm}$ to $1,2 \mathrm{MIm}$ increased toxicity. Im and 1,4,5MIm were the most toxic compounds investigated. 2-Alkylimidazoles were less toxic than $2-\mathrm{H}$ imidazoles. Longer alkyl groups reduced the toxicity until $\mathrm{C}_{3-5}$, after which the toxicity rose. Cell viability is plotted against predicted octane-water partition coefficient, cLogP, in Figure 8. cLogP values were calculated using ChemBioDraw Ultra 14. cLoP is a measure of the hydrophobicity of compounds. Larger cLogP values indicated increased hydrophobic character. More hydrophobic compounds are more easily taken up in ground water, and more toxic to animals and aquatic life. ${ }^{46}$ When cLogP was above 3 , the cell viability and $\operatorname{cLogP}$ values negatively correlated. Lipophilic imidazoles, $\operatorname{cLogP}>3$, can potentially absorb into the lipid membrane, disrupting the cell membrane, similar to the effect of clotrimazole. ${ }^{47}$ Alkyl imidazolium-based ionic liquids are increasingly toxic with alkyl-chain length, as observed for alkylimidazoles. ${ }^{25}$, 27 2-Methyl imidazoles are less polar than 2-H imidazoles, in accordance with predicted cLogP values, which 
can explain the increased toxicity of the long-chained structures $1 \mathrm{Hp} 4,5 \mathrm{MIm}$ and $104,5 \mathrm{MIm}$ compared to $1 \mathrm{Hp} 2,4,5 \mathrm{MIm}$ and 102,4,5MIm (Figures 7 and 8).

As shown in Figure 8, there is no clear correlation between the cLogP values and the PC-12 cell viability, except cases stated above. The poor correlation suggests that there are multiple modes of toxicity for the imidazoles or that the properties of the imidazoles changed drastically with structure. The toxicological screening indicate that polyalkylimidazole are less toxic compared to Im. Hence, polyalkylated imidazoles are considered non-toxic or mild irritants, with no apparent pathway of toxicity apart from lipid membrane interactions. This consideration should not be taken as absolute, as both $2 \mathrm{MIm}^{31}$ and $4 \mathrm{MIm}^{32}$ are considered to be potential carcinogens.

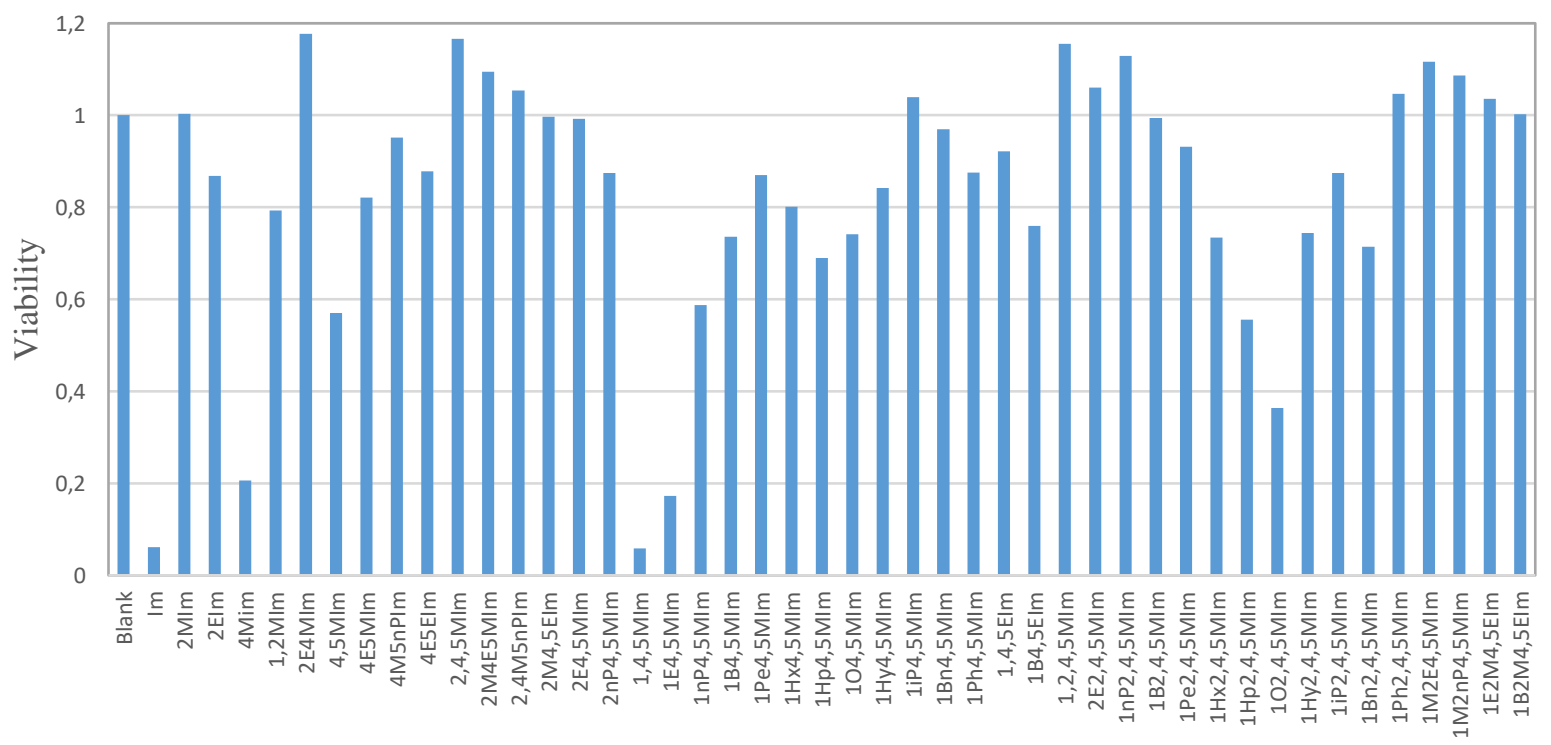

Figure 7: Toxicological screening; Viability of PC-12 cells after exposure to $100 \mu \mathrm{M}$ (alkyl)imidazole solution for $24 \mathrm{~h}$ measured using the MTT assay.

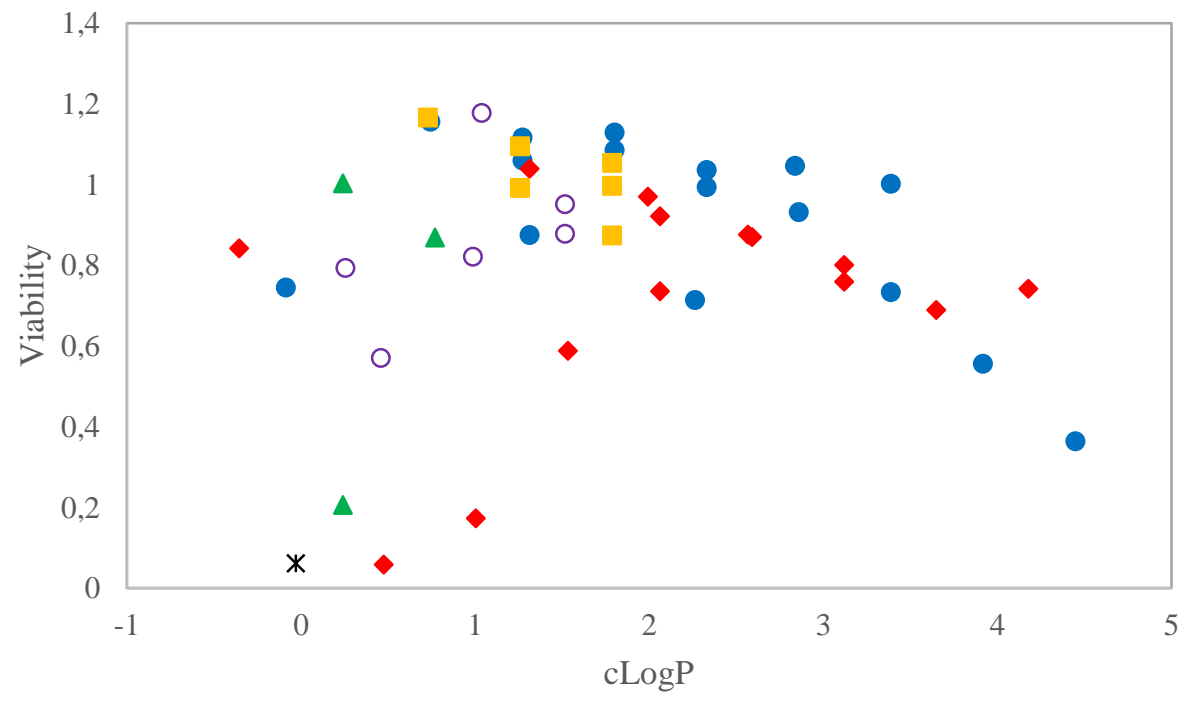


Figure 8: Plot of viability of PC-12 cells against cLogP values calculated for alkylated imidazoles by ChemBioDraw Ultra 14. Im; $*$, monosubstituted; $\Delta$, disubstituted; $\bigcirc, 2,4,5$-trisubstituted; orange $\square, 1,4,5$-trisubstituted; $\diamond$, 1,2,4,5-tetrasubstituted $\bigcirc$.

In addition to the toxicity of the imidazole in the solvent, the formed imidazole degradation products contribute to the hazardous character of the solvent. By using Table 2, devised from Scheme 1-4, it is possible to predict likely degradation products from different imidazoles in $\mathrm{CO}_{2}$ containing systems. Imidazoles with longer alkyl chain lengths are assumed to be able to degrade by the same pathways as the imidazoles investigated in the degradation part of this study. The associated hazards listed in Table 2, show that most of the formed compounds are corrosive and a large number are toxic. 2-H imidazoles may release formaldehyde during degradation, a potential carcinogen, which should be avoided if possible. Formamide and acetamide, two other possible carcinogens were demonstrated as degradation products in this work. The concentration of acetamide in the degraded $2,4,5 \mathrm{MIm}$ solution was as high as $0.97 \mathrm{M}$, Figure 6 . Consequently, the waste from an imidazole solvent may require special treatment, raising the price of waste handling. Opening of the imidazole ring, Scheme 1, produces ammonia and other low molecular weight alkylamines that may rapidly evaporate from the solution. Most of the degradation products are more volatile than the imidazoles themselves, ${ }^{16,33}$ and a water wash is required to prevent airborne emissions of degradation products. From the degradation study and assessment of the imidazole degradation products, it appears that imidazoles are poorly suited towards $\mathrm{CO}_{2}$ applications.

Table 2: The associated hazards of observed and potential degradation products from imidazole degradation under $\mathrm{CO}_{2}$ capture conditions, and the responsible imidazole functionalization.

\begin{tabular}{|c|c|c|}
\hline Compound & Degradation product of & Associated hazards ${ }^{\mathrm{a}}$ \\
\hline Formic acid & 2-H, 4-H and 5-H imidazoles & Toxic, corrosive, and flammable \\
\hline Acetic acid & 2-Me, 4-Me and 5-Me imidazoles & Corrosive and flammable \\
\hline Propionic acid & 2-Et, 4-Et and 5-Et imidazoles & Irritant, corrosive and flammable \\
\hline $\begin{array}{c}\mathrm{C}_{4} \text { and longer carboxylic } \\
\text { acids }\end{array}$ & $\begin{array}{l}\text { Imidazoles with } \mathrm{C}_{3} \text { or longer alkyl } \\
\text { chains in } 2,4 \text { or } 5 \text { position }\end{array}$ & Corrosive and flammable \\
\hline Formamide & $\begin{aligned} 1-\mathrm{Me}, & 2-\mathrm{H}, 4-\mathrm{H} \text { and } 5-\mathrm{H} \\
& \text { imidazoles }\end{aligned}$ & $\begin{array}{c}\text { Potentially carcinogenic, reproductive } \\
\text { toxicity }\end{array}$ \\
\hline Acetamide & 2-Me, 4-Me and 5-Me imidazoles & Potentially carcinogenic \\
\hline Propylamide & $1-n-\operatorname{Pr}$ imidazoles & None \\
\hline $\mathrm{C}_{4}$ and longer amides & 1-alkyl imidazoles & None \\
\hline$N$-methylformamide & 2-H-1-Me imidazoles & Harmful, may damage the unborn child \\
\hline$N$-methylacetamide & 1,2-Me imidazoles & May damage the unborn child \\
\hline Oxalic acid & 4,5-H imidazoles & Harmful, corrosive \\
\hline Formaldehyde & 2-H imidazoles & $\begin{array}{l}\text { Toxic, potentially carcinogenic, } \\
\text { corrosive, flammable }\end{array}$ \\
\hline Acetaldehyde & 2-Me imidazoles & $\begin{array}{l}\text { Toxic, potentially carcinogenic, } \\
\text { reproductive toxicity, flammable }\end{array}$ \\
\hline Propionaldehyde & 2-Et imidazoles & Irritant, corrosive, flammable \\
\hline $\mathrm{C}_{4}$ and longer aldehydes & 2-alkyl imidazoles & Irritant, flammable \\
\hline Glyoxal & 4,5-H imidazoles & Harmful, irritant, reproductive toxicity \\
\hline Acetylformaldehyde & 4(5)-H-5(4)-Me imidazoles & $\begin{array}{l}\text { Harmful, irritant, corrosive, } \\
\text { reproductive toxicity }\end{array}$ \\
\hline 2,3-Butanedione & 4,5-Me imidazoles & Toxic, flammable \\
\hline Ammonia & All imidazoles & $\begin{array}{l}\text { Toxic, toxic for aquatic life, corrosive, } \\
\text { flammable }\end{array}$ \\
\hline Methylamine & 1-Me imidazoles & Toxic, corrosive, flammable \\
\hline
\end{tabular}




\begin{tabular}{ccc}
\hline Ethylamine & 1 -Et imidazoles & Toxic, corrosive, flammable \\
Propylamine & $1-n$-Pr imidazoles & Toxic, corrosive, flammable \\
$\mathrm{C}_{4}$ and longer amines & 1 -alkyl imidazoles & Toxic, toxic for aquatic life, corrosive, \\
& flammable
\end{tabular}

a) Associated hazards collected from Safety Data Sheets from Sigma-Aldrich. For $\mathrm{C}_{4}$ and longer, all sheets from $\mathrm{C}_{4-8}$ were collected and all reported hazards were included.

\section{Conclusions}

The (alkyl)imidazoles are more resistant towards thermal degradation than comparable amines. Both Im and 2MIm were highly corrosive in $30 \mathrm{wt} \%$ aqueous solutions, whereas the alkaline imidazoles more successfully inhibited corrosion during degradation experiments. The tendency of the imidazoles to oxidize increased with alkyl-substitution, and is explained by higher electron density of the ring moiety. Appropriate oxidation inhibitors are required for industrial application of polyalkylated imidazoles due to their low oxidative stability. Low toxicity was observed for polyalkylated imidazoles, with the exception of longer chained derivatives. The present study on alkylimidazoles contributes to improved understanding of the behavior of these compounds in industrial processes and addresses the potential hazards of these compounds and the degradation products thereof. Although imidazoles possess interesting properties as absorbents, the high rate of degradation under oxidative conditions, during which potential carcinogens are formed, will prevent their feasibility as absorbents for $\mathrm{CO}_{2}$ capture.

\section{Author Information}

All authors have given approval to the final version of the manuscript.

\section{Corresponding author}

Hanna K. Knuutila: hanna.knuutila@ntnu.no

\section{Acknowledgements}

The authors would like to acknowledge the financial support of the Research Council of Norway, through CLIMIT grant 233776.

Syverin Lierhagen is acknowledged for running ICP-MS experiments. Susana Villa Gonzalez is recognized for obtaining LC-HRMS spectra. Torun Margareta Melø is thanked for helping to develop the NMR method.

\section{Supporting Information}

The Supporting Information is available free of charge on the ACS Publications website at DOI:

- List of polyalkylated imidazoles included in the toxicological screening

- Concentrations and NMR shift assignments of degradation products in the imidazole solutions following the oxidative degradation experiments

- ${ }^{1} \mathrm{H}$ and ${ }^{13} \mathrm{C}$ NMR spectra of degraded imidazole samples

\section{References}

1. Rochelle, G. T., Amine Scrubbing for CO2; Capture. Science 2009, 325, 1652.

2. Davis, J.; Rochelle, G., Thermal degradation of monoethanolamine at stripper conditions. Energy Procedia 2009, 1, 327-333. 
3. Lepaumier, H.; da Silva, E. F.; Einbu, A.; Grimstvedt, A.; Knudsen, J. N.; Zahlsen, K.; Svendsen, H. F., Comparison of MEA degradation in pilot-scale with lab-scale experiments. Energy Procedia 2011, 4, 1652-1659.

4. Gouedard, C.; Picq, D.; Launay, F.; Carrette, P. L., Amine degradation in CO2 capture. I. A review. Int. J. Greenhouse Gas Control 2012, 10, 244-270.

5. Islam, M. S.; Yusoff, R.; Ali, B. S.; Islam, M. N.; Chakrabarti, M. H., Degradation studies of amines and alkanolamines during sour gas treatment process. Int. J. Phys. Sci. 2011, 6, 5883-5896.

6. $\quad$ Eide-Haugmo, I.; Brakstad, O. G.; Hoff, K. A.; Sørheim, K. R.; da Silva, E. F.; Svendsen, H. F., Environmental impact of amines. Energy Procedia 2009, 1, 1297-1304.

7. Fytianos, G.; Grimstvedt, A.; Knuutila, H.; Svendsen, H. F., Effect of MEA's degradation products on corrosion at CO2 capture plants. Energy Procedia 2014, 63, 1869-1875.

8. da Silva, E. F.; Kolderup, H.; Goetheer, E.; Hjarbo, K. W.; Huizinga, A.; Khakharia, P.; Tuinman, I.; Mejdell, T.; Zahlsen, K.; Vernstad, K.; Hyldbakk, A.; Holten, T.; Kvamsdal, H. M.; van Os, P.; Einbu, A., Emission studies from a CO2 capture pilot plant. Energy Procedia 2013, 37, 778-783.

9. $\quad$ Puxty, G.; Conway, W.; Botma, H.; Feron, P.; Maher, D.; Wardhaugh, L., A New CO2 Absorbent Developed from Addressing Benzylamine Vapour Pressure Using Co-solvents. Energy Procedia 2017, 114, 1956-1965.

10. Shannon, M. S.; Bara, J. E., Properties of Alkylimidazoles as Solvents for CO2 Capture and Comparisons to Imidazolium-Based Ionic Liquids. Ind. Eng. Chem. Res. 2011, 50, 8665-8677.

11. Bara, J. E. N-functionalized imidazole-containing systems and methods of use. US8741246, 2014.

12. Puxty, G.; Conway, W.; Yang, Q.; Feron, P. H. M. Process and system for capture of carbon dioxide. WO2018213873, 2018.

13. Shannon, M. S.; Bara, J. E., Reactive and Reversible Ionic Liquids for CO2 Capture and Acid Gas Removal. Sep. Sci. Techn. 2012, 47, 178-188.

14. Du, Y.; Wang, Y.; Rochelle, G. T., Thermal degradation of novel piperazine-based amine blends for CO2 capture. Int. J. Greenhouse Gas Control 2016, 49, 239-249.

15. Evjen, S.; Fiksdahl, A.; Pinto, D. D. D.; Knuutila, H. K., New polyalkylated imidazoles tailored for carbon dioxide capture. Int. J. Greenhouse Gas Control 2018, 76, 167-174.

16. Evjen, S.; Wanderley, R.; Fiksdahl, A.; Knuutila, H. K., Viscosity, Density, and Volatility of Binary Mixtures of Imidazole, 2-Methylimidazole, 2,4,5-Trimethylimidazole, and 1,2,4,5-Tetramethylimidazole with Water. J. Chem. Eng. Data 2019, 64, 507-516.

17. Evjen, S.; Løge, O. S.; Fiksdahl, A.; Knuutila, H. K., Aminoalkyl-Functionalized Pyridines as High Cyclic Capacity CO2 Absorbents. Energy Fuels 2019, 33, 10011-10015.

18. Bara, J. E. Gas treating solutions containing imidazole-amine compounds. US10350544B2, 2015.

19. Wanderley, R. R.; Yuan, Y.; Rochelle, G. T.; Knuutila, H. K., CO2 solubility and mass transfer in water-lean solvents. Chem. Eng. Sci. 2019, 202, 403-416.

20. Ramdin, M.; de Loos, T. W.; Vlugt, T. J. H., State-of-the-Art of CO2 Capture with Ionic Liquids. Ind. Eng. Chem. Res. 2012, 51, 8149-8177.

21. Aghaie, M.; Rezaei, N.; Zendehboudi, S., A systematic review on $\mathrm{CO} 2$ capture with ionic liquids: Current status and future prospects. Renewable Sustainable Energy Rev. 2018, 96, 502-525.

22. Domínguez, C. M.; Munoz, M.; Quintanilla, A.; de Pedro, Z. M.; Casas, J. A., Kinetics of imidazolium-based ionic liquids degradation in aqueous solution by Fenton oxidation. Environ. Sci. Pollution Res. 2018, 25, 3481134817 .

23. Long, H.; Pivovar, B., Hydroxide Degradation Pathways for Imidazolium Cations: A DFT Study. J. Phys. Chem. C 2014, 118, 9880-9888.

24. Mahrova, M.; Conte, M.; Roman, E.; Nevshupa, R., Critical Insight into Mechanochemical and Thermal Degradation of Imidazolium-Based Ionic Liquids with Alkyl and Monomethoxypoly(ethylene glycol) Side Chains. $J$. Phys. Chem. C 2014, 118, 22544-22552.

25. Zhang, C.; Zhu, L.; Wang, J.; Wang, J.; Zhou, T.; Xu, Y.; Cheng, C., The acute toxic effects of imidazoliumbased ionic liquids with different alkyl-chain lengths and anions on zebrafish (Danio rerio). Ecotoxicol. Environ. Saf. 2017, 140, 235-240.

26. Liu, T.; Zhu, L.; Wang, J.; Wang, J.; Zhang, J.; Sun, X.; Zhang, C., Biochemical toxicity and DNA damage of imidazolium-based ionic liquid with different anions in soil on Vicia faba seedlings. Sci. Rep. 2015, 5, 18444.

27. Romero, A.; Santos, A.; Tojo, J.; Rodríguez, A., Toxicity and biodegradability of imidazolium ionic liquids. J. Haz. Mat. 2008, 151, 268-273.

28. Martin, S.; Lepaumier, H.; Picq, D.; Kittel, J.; de Bruin, T.; Faraj, A.; Carrette, P.-L., New Amines for CO2 Capture. IV. Degradation, Corrosion, and Quantitative Structure Property Relationship Model. Ind. Eng. Chem. Res. 2012, 51, 6283-6289. 
29. Ebel, K.; Koehler, H.; Gamer, A. O.; Jäckh, R., Imidazole and Derivatives. In Ullmann's Encyclopedia of Industrial Chemistry 2000, 18, 637-645.

30. Nishie, K.; Waiss, A. C.; Keyl, A. C., Toxicity of methylimidazoles. Toxicol. Appl. Pharmacol. 1969, 14, 301-307.

31. National Toxicology Program. NTP TECHNICAL REPORT ON THE TOXICOLOGY AND CARCINOGENESIS STUDIES OF 2-METHYLIMIDAZOLE IN F344/N RATS AND B6C3F MICE; National Toxicology Program, U.S. Dept. of Health and Human Services, National Institutes of Health: Research Triangle Park, NC, 2004

32. Chan, P. C.; Hills, G. D.; Kissling, G. E.; Nyska, A., Toxicity and carcinogenicity studies of 4methylimidazole in F344/N rats and B6C3F1 mice. Arch. Toxicol. 2008, 82, 45-53.

33. Evjen, S.; Fiksdahl, A., Syntheses of polyalkylated imidazoles. Synth. Commun. 2017, 47, $1392-1399$.

34. Shoukat, U.; Baumeister, E.; Pinto, D. D. D.; Knuutila, H. K., Thermal stability and corrosion of tertiary amines in aqueous amine and amine-glycol-water solutions for combined acid gas and water removal. J. Nat. Gas Sci. Eng. 2019, 62, 26-37.

35. Fytianos, G.; Ucar, S.; Grimstvedt, A.; Hyldbakk, A.; Svendsen, H. F.; Knuutila, H. K., Corrosion and degradation in MEA based post-combustion CO2 capture. Int. J. Greenhouse Gas Control 2016, 46, 48-56.

36. Fytianos, G.; Vevelstad, S. J.; Knuutila, H. K., Degradation and corrosion inhibitors for MEA-based CO2 capture plants. Int. J. Greenhouse Gas Control 2016, 50, 240-247.

37. Chi, S.; Rochelle, G. T., Oxidative Degradation of Monoethanolamine. Ind. Eng. Chem. Res. 2002, 41, 41784186.

38. Du, Y.; Wang, Y. K.; Rochelle, G. T., Thermal degradation of novel piperazine-based amine blends for CO2 capture. Int. J. Greenhouse Gas Control 2016, 49, 239-249.

39. Fytianos, G.; Grimstvedt, A.; Knuutila, H.; Svendsen, H. F., Effect of MEA's Degradation Products on Corrosion at CO2 Capture Plants. Energy Procedia 2014, 63, 1869-1875.

40. Eide-Haugmo, I. Environmental impacts and aspects of absorbents used for $\mathrm{CO}_{2}$ capture. Norwegian University of Science and Technology, Trondheim, Norway, 2011.

41. Gridnev, A. A.; Mihaltseva, I. M., Synthesis of 1-Alkylimidazoles. Synth. Commun. 1994, 24, 1547-1555.

42. Gao, H. X.; Liang, Z. W.; Liao, H. Y.; Idem, R. O., Thermal degradation of aqueous DEEA solution at stripper conditions for post-combustion CO2 capture. Chem. Eng. Sci. 2015, 135, 330-342.

43. McCafferty, E., Introduction to Corrosion Science. Springer: New York, 2010.

44. Nielsen, P. T.; Rochelle, G. T., Effects of Catalysts, Inhibitors, and Contaminants on Piperazine Oxidation. Energy Procedia 2017, 114, 1919-1929.

45. Dalvie, D. K.; Kalgutkar, A. S.; Khojasteh-Bakht, S. C.; Obach, R. S.; O'Donnell, J. P., Biotransformation Reactions of Five-Membered Aromatic Heterocyclic Rings. Chem. Res. Toxicol. 2002, 15, 269-299.

46. Mark, T. D. C., The Role of Hydrophobicity in Toxicity Prediction. Current Computer-Aided Drug Design 2006, 2 (4), 405-413.

47. Kasper, L.; Miramón, P.; Jablonowski, N.; Wisgott, S.; Wilson, D.; Brunke, S.; Hube, B., Antifungal activity of clotrimazole against Candida albicans depends on carbon sources, growth phase and morphology. J. Med. Microbiol. 2015, 64, 714-723.. 
TOC Graphic

IMIDAZOLES FOR

POST COMBUSTION

$\mathrm{CO}_{2}$ CAPTURE

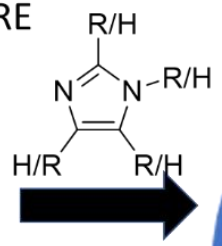

$\mathrm{CO}_{2}$
THERMAL DEGRADATION

- OXIDATIVE DEGRADATION - TOXICITY

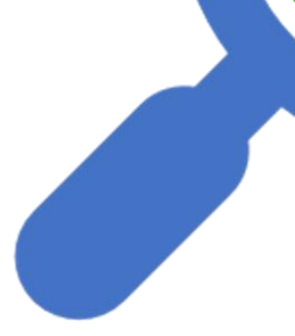

HOH

$\mathrm{R}_{\mathrm{OH}}^{\mathrm{O}} \mathrm{H}_{\mathrm{H}}$

$\Rightarrow$ a

- IDENTIFICATION OF DEGRADATION PRODUCTS

- FEASIBILITY OF USE IN INDUSTRIAL PROCESS 
Supporting Information

\section{Degradative behavior and toxicity of alkylated imidazoles}

Sigvart Evjen ${ }^{\mathrm{a}}$, Ove Alexander Høgmoen Åstrand ${ }^{\mathrm{b}}$, Mona Gaarder ${ }^{\mathrm{c}}$, Ragnhild E. Paulsen ${ }^{\mathrm{c}}$, Anne Fiksdahl $^{\text {a }}$, Hanna K. Knuutila ${ }^{\mathrm{d} *}$

a) Department of Chemistry, Norwegian University of Science and Technology (NTNU), 7491 Trondheim, Norway

b) Department of Pharmaceutical Chemistry, School of Pharmacy, University of Oslo, 0316, Oslo, Norway

c) Department of Pharmaceutical Biosciences, School of Pharmacy, University of Oslo, 0316, Oslo, Norway

d) Department of Chemical Engineering, Norwegian University of Science and Technology (NTNU), 7034 Trondheim, Norway 

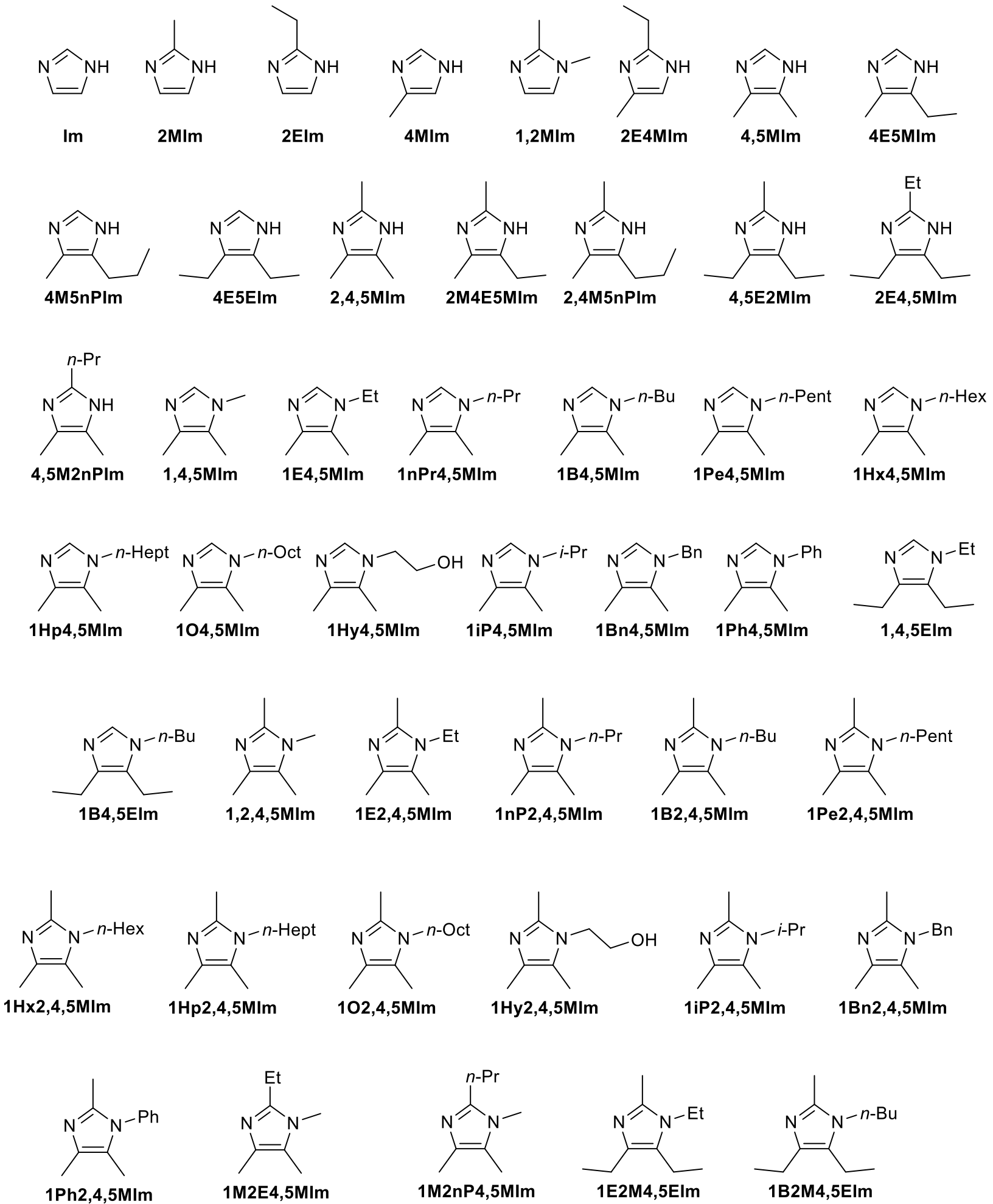

Figure S1. Overview of screened imidazoles in toxicology screening. 
Table S1. Degradation compound peak assignment and relative quantities to Im in solution at the end of oxidative degradation experiments.

\begin{tabular}{ccccc}
\hline Compound & ${ }^{1} \mathrm{H}$ & ${ }^{13} \mathrm{C}$ & $\mathrm{m} / \mathrm{z}^{a}$ & $\begin{array}{c}\text { Concentration } \\
{[\mathrm{mol} / \mathrm{kg}]}\end{array}$ \\
\hline $\mathrm{Im}$ & $7.44,6.80$ & $138.46,124.33$ & - & 4.30 \\
Formic acid $^{\mathrm{HCO}_{3}{ }^{-}}$ & 8.35 & 173.52 & - & 0.009 \\
Oxalic acid $^{-}$ & - & 163.71 & - & 0.062 \\
\hline
\end{tabular}

${ }^{a}$ Observed HRMS peak in bracket.

Table S2. Degradation compound peak assignment and relative quantities to $2 \mathrm{MIm}$ in solution at the end of oxidative degradation experiments.

\begin{tabular}{ccccc}
\hline Compound & ${ }^{1} \mathrm{H}$ & ${ }^{13} \mathrm{C}$ & $\mathrm{m} / \mathrm{z}$ & $\begin{array}{c}\text { Concentration } \\
{[\mathrm{mol} / \mathrm{kg}]}\end{array}$ \\
\hline $2 \mathrm{MIm}$ & $6.73,2.16$ & $148.06,123.54$ & - & 2.79 \\
Formic acid & 8.39 & 14.93 & - & 0.106 \\
Formamide & 7.88 & 173.44 & - & 0.014 \\
$\mathrm{HCO}_{3}^{-}$ & - & 169.23 & - & 0.120 \\
Acetamide & 1.79 & 163.88 & - & 0.259 \\
Oxalic acid & - & $179.73,24.11$ & - & 0.056 \\
Acetic acid & 1.81 & 176.02 & - & 0.017 \\
\hline
\end{tabular}


Table S3. Degradation compound peak assignment and relative quantities to 2E4MIm in solution at the end of oxidative degradation experiments.

\begin{tabular}{|c|c|c|c|c|}
\hline Compound & ${ }^{1} \mathrm{H}$ & ${ }^{13} \mathrm{C}$ & $\mathrm{m} / \mathrm{z}^{a}$ & $\begin{array}{l}\text { Concentration } \\
{[\mathrm{mol} / \mathrm{kg}]}\end{array}$ \\
\hline 2E4MIm & $\begin{array}{c}6.48,2.52,1.96 \\
1.06\end{array}$ & $\begin{array}{c}152.18,133.59 \\
118.80,23.17 \\
14.42,13.02\end{array}$ & & 2.08 \\
\hline $\mathrm{HCO}_{3}^{-}$ & & 163.49 & & 0.110 \\
\hline Acetic acid & 1.83 & $183.39,26.37$ & & 0.26 \\
\hline Propionic acid & $2.06,0.92$ & $\begin{array}{c}186.71,33.63, \\
13.08\end{array}$ & & 0.133 \\
\hline Acetamide & 1.83 & $179.51,24.16$ & & 0.264 \\
\hline Propylamide & $2.08,0.92$ & $\begin{array}{c}183.13,31.23 \\
12.16\end{array}$ & & 0.312 \\
\hline $\begin{array}{l}\text { Formic acid } \\
\text { Oxalic acid }\end{array}$ & 8.43 & $\begin{array}{l}173.12 \\
175.99\end{array}$ & \multirow[b]{2}{*}{$\begin{array}{c}87.0084 \mathrm{C}_{3} \mathrm{H}_{4} \mathrm{O}_{3} \\
(\mathrm{M}+\mathrm{H})\end{array}$} & $\begin{array}{l}0.025 \\
0.002\end{array}$ \\
\hline 2-Oxopropanoic acid & - & - & & - \\
\hline & & & $\begin{array}{c}127.0867 \\
\mathrm{C}_{6} \mathrm{H}_{10} \mathrm{~N}_{2} \mathrm{O} \\
(\mathrm{M}+\mathrm{H})\end{array}$ & \\
\hline $\mathrm{NH}$ & & & $\begin{array}{c}127.0867 \\
\mathrm{C}_{6} \mathrm{H}_{10} \mathrm{~N}_{2} \mathrm{O} \\
(\mathrm{M}+\mathrm{H})\end{array}$ & \\
\hline $\mathrm{N}^{\prime} \mathrm{NH}$ & & & $\begin{array}{c}125.0711 \mathrm{C}_{6} \mathrm{H}_{8} \mathrm{~N}_{2} \mathrm{O} \\
(\mathrm{M}+\mathrm{H})\end{array}$ & \\
\hline Proposed & & & & \\
\hline
\end{tabular}

${ }^{a}$ Observed HRMS peak in bracket. 
Table S4. Degradation compound peak assignment and relative quantities to 2,4,5MIm in solution at the end of oxidative degradation experiments.

\begin{tabular}{|c|c|c|c|c|}
\hline Compound & ${ }^{1} \mathrm{H}$ & ${ }^{13} \mathrm{C}$ & $\mathrm{m} / \mathrm{z}^{a}$ & $\begin{array}{c}\text { Concentration } \\
{[\mathrm{mol} / \mathrm{kg}]}\end{array}$ \\
\hline 2,4,5MIm & $2.40,2.04$ & $\begin{array}{c}144.34,126.69 \\
13.53,10.82\end{array}$ & & 0.826 \\
\hline $\mathrm{HCO}_{3}^{-}$ & & & & 0.005 \\
\hline Formic acid & 8.40 & 173.22 & & 0.028 \\
\hline Acetic acid & 1.84 & $183.54,26.03$ & & 0.884 \\
\hline Acetamide & 1.89 & $179.68,24.20$ & & 0.967 \\
\hline Oxalic acid & - & - & - & - \\
\hline & $4.86,2.45,2.09$ & $\begin{array}{c}\text { 145.10, 129.54 } \\
\text { 127.78, 13.73 } \\
11.31\end{array}$ & $\begin{array}{c}127.0867 \\
\mathrm{C}_{6} \mathrm{H}_{10} \mathrm{~N}_{2} \mathrm{O} \\
(\mathrm{M}+\mathrm{H})\end{array}$ & 0.173 \\
\hline Unknown & $2.81,2.41,1.18^{b}$ & $\begin{array}{c}220.20,181.00 \\
81.10,49.12,26.80\end{array}$ & & 0.057 \\
\hline & & & $\begin{array}{c}123.0554 \\
\mathrm{C}_{6} \mathrm{H}_{8} \mathrm{~N}_{2} \mathrm{O}_{2}(\mathrm{M}+\mathrm{H}- \\
\left.\mathrm{H}_{2} \mathrm{O}\right)\end{array}$ & \\
\hline & & & $\begin{array}{c}123.0554 \\
\mathrm{C}_{6} \mathrm{H}_{8} \mathrm{~N}_{2} \mathrm{O}_{2}(\mathrm{M}+\mathrm{H}- \\
\left.\mathrm{H}_{2} \mathrm{O}\right)\end{array}$ & \\
\hline $\mathrm{NH}_{2}$ & & & $\begin{array}{c}\text { 70.0653 } \mathrm{C}_{4} \mathrm{H}_{9} \mathrm{NO} \\
\left(\mathrm{M}+\mathrm{H}-\mathrm{H}_{2} \mathrm{O}\right)\end{array}$ & \\
\hline Proposed & & & & \\
\hline
\end{tabular}

${ }^{a}$ Observed HRMS peak in bracket.

${ }^{b}$ One or more NMR signals may be missing. 
Table S5. Degradation compound peak assignment and relative quantities to $1,2,4,5 \mathrm{MIm}$ in solution at the end of oxidative degradation experiments.

\begin{tabular}{|c|c|c|c|c|}
\hline Compound & ${ }^{1} \mathrm{H}$ & ${ }^{13} \mathrm{C}$ & $\mathrm{m} / \mathrm{z}^{a}$ & $\begin{array}{c}\text { Concentration } \\
{[\mathrm{mol} / \mathrm{kg}]}\end{array}$ \\
\hline 1,2,4,5MIm & $\begin{array}{c}3.42,2.40,2.04, \\
2.03\end{array}$ & $\begin{array}{c}145.01,127.91 \\
127.77,33.21 \\
13.41,11.90,10.28\end{array}$ & & 0.490 \\
\hline $\mathrm{HCO}_{3}^{-}$ & & 163.01 & & 0.076 \\
\hline Formic acid & & 173.08 & & 0.019 \\
\hline Acetic acid & 1.83 & $183.36,26.28$ & & 0.549 \\
\hline Acetamide & 1.90 & $179.64,24.21$ & & 0.509 \\
\hline Oxalic acid & - & - & & - \\
\hline$N$-methylacetamide & $2.84,2.16$ & $\begin{array}{c}168.37,32.16 \\
20.10\end{array}$ & & 0.265 \\
\hline & $7.57,3.45,1.99^{b}$ & $\begin{array}{c}137.67,133.25 \\
127.20,34.19 \\
13.14^{b}\end{array}$ & & 0.029 \\
\hline Unknown & $2.81,2.41,1.18^{c}$ & $\begin{array}{c}220.27,180.97 \\
81.07,49.21,26.87\end{array}$ & & 0.068 \\
\hline & & & $\begin{array}{c}137.0711 \\
\mathrm{C}_{7} \mathrm{H}_{10} \mathrm{~N}_{2} \mathrm{O}_{2}(\mathrm{M}+\mathrm{H}- \\
\left.\mathrm{H}_{2} \mathrm{O}\right)\end{array}$ & \\
\hline $\mathrm{NH}_{2}$ & & & $\begin{array}{c}70.0653 \\
\mathrm{C}_{4} \mathrm{H}_{9} \mathrm{NO}(\mathrm{M}+\mathrm{H}- \\
\left.\mathrm{H}_{2} \mathrm{O}\right)\end{array}$ & \\
\hline Proposed & & & & \\
\hline
\end{tabular}

${ }^{a}$ Observed HRMS peak in bracket.

${ }^{b}$ One NMR signal missing.

${ }^{c}$ One or more NMR signals may be missing. 
${ }^{1} \mathrm{H}$ and ${ }^{13} \mathrm{C}$ NMR of Im after oxidative degradation experiment

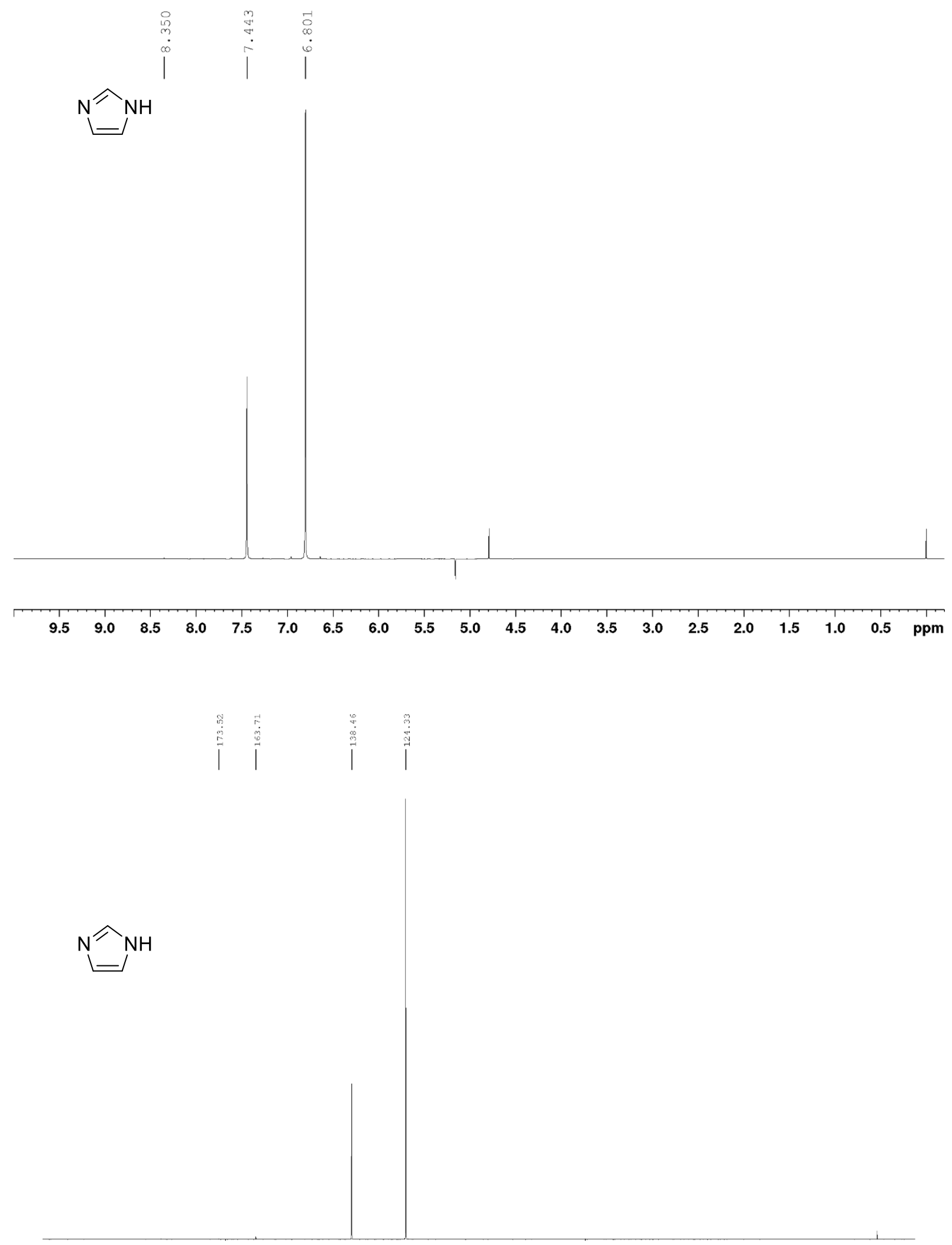

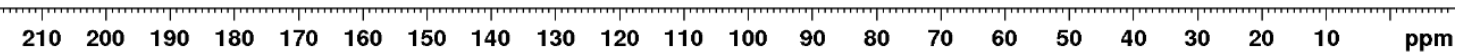


${ }^{1} \mathrm{H}$ and ${ }^{13} \mathrm{C}$ NMR of $2 \mathrm{MIm}$ after oxidative degradation experiment
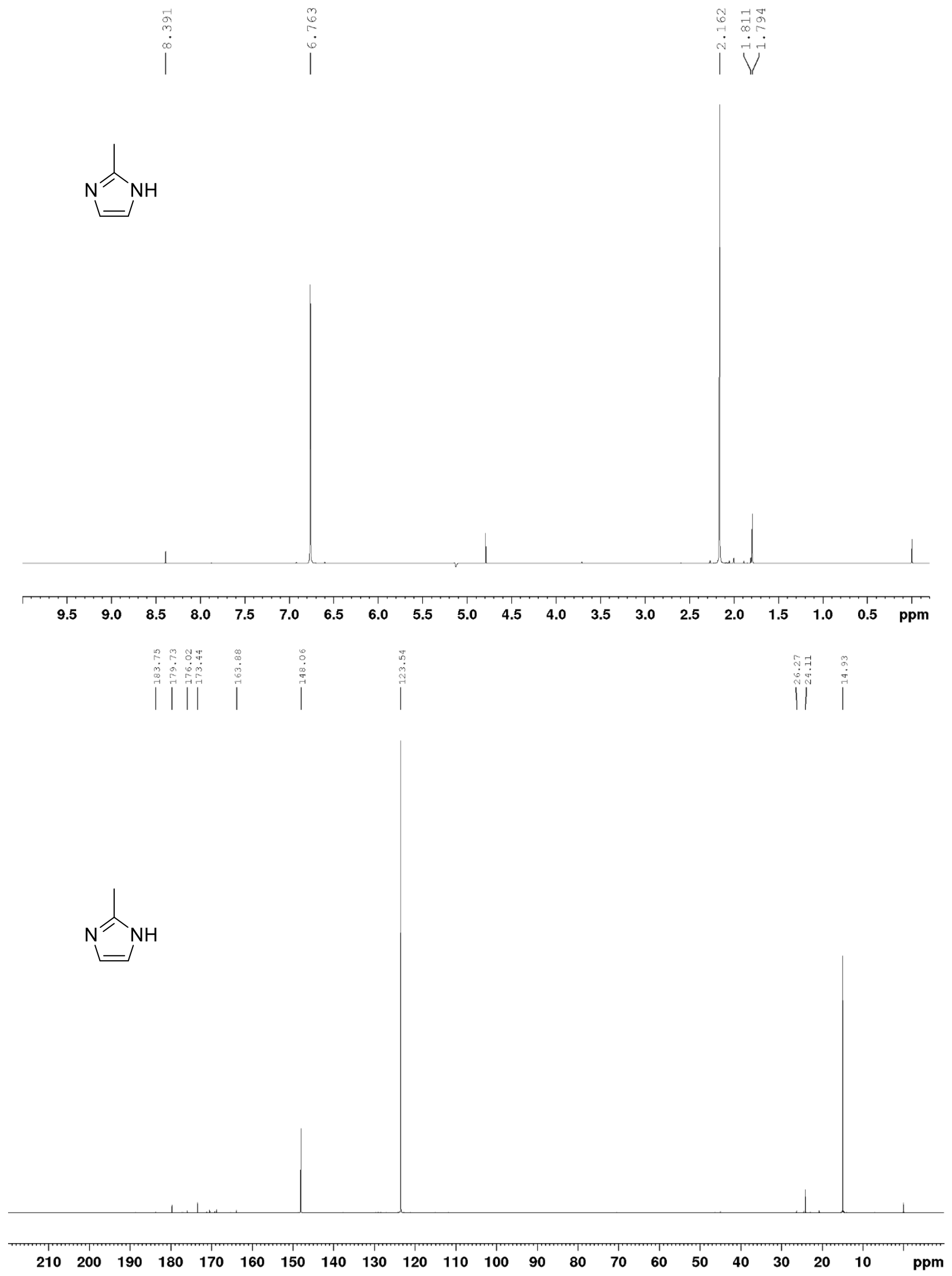
${ }^{1} \mathrm{H}$ and ${ }^{13} \mathrm{C}$ NMR of 2E4MIm after oxidative degradation experiment
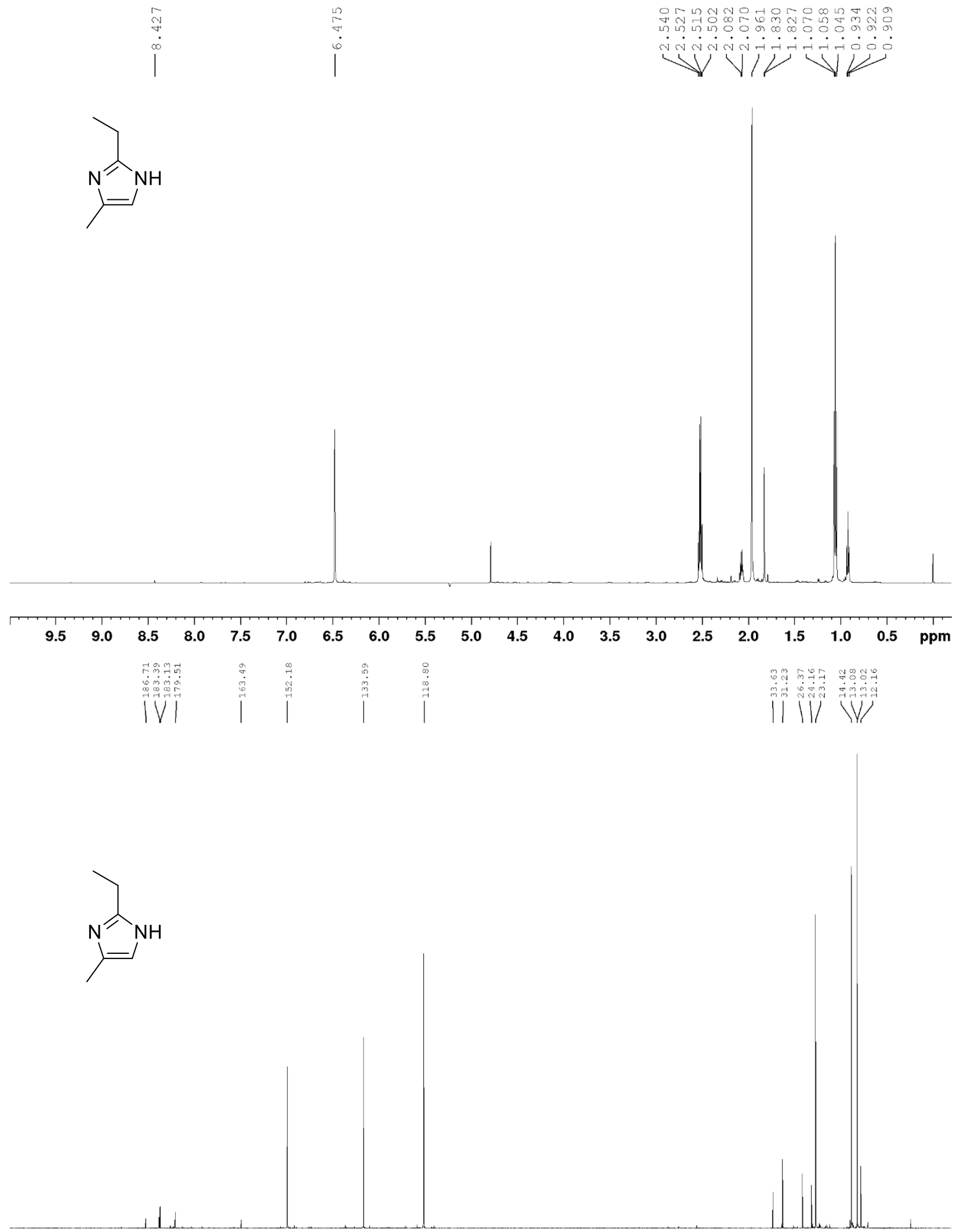
${ }^{1} \mathrm{H}$ and ${ }^{13} \mathrm{C}$ NMR of 2,4,5MIm after oxidative degradation experiment

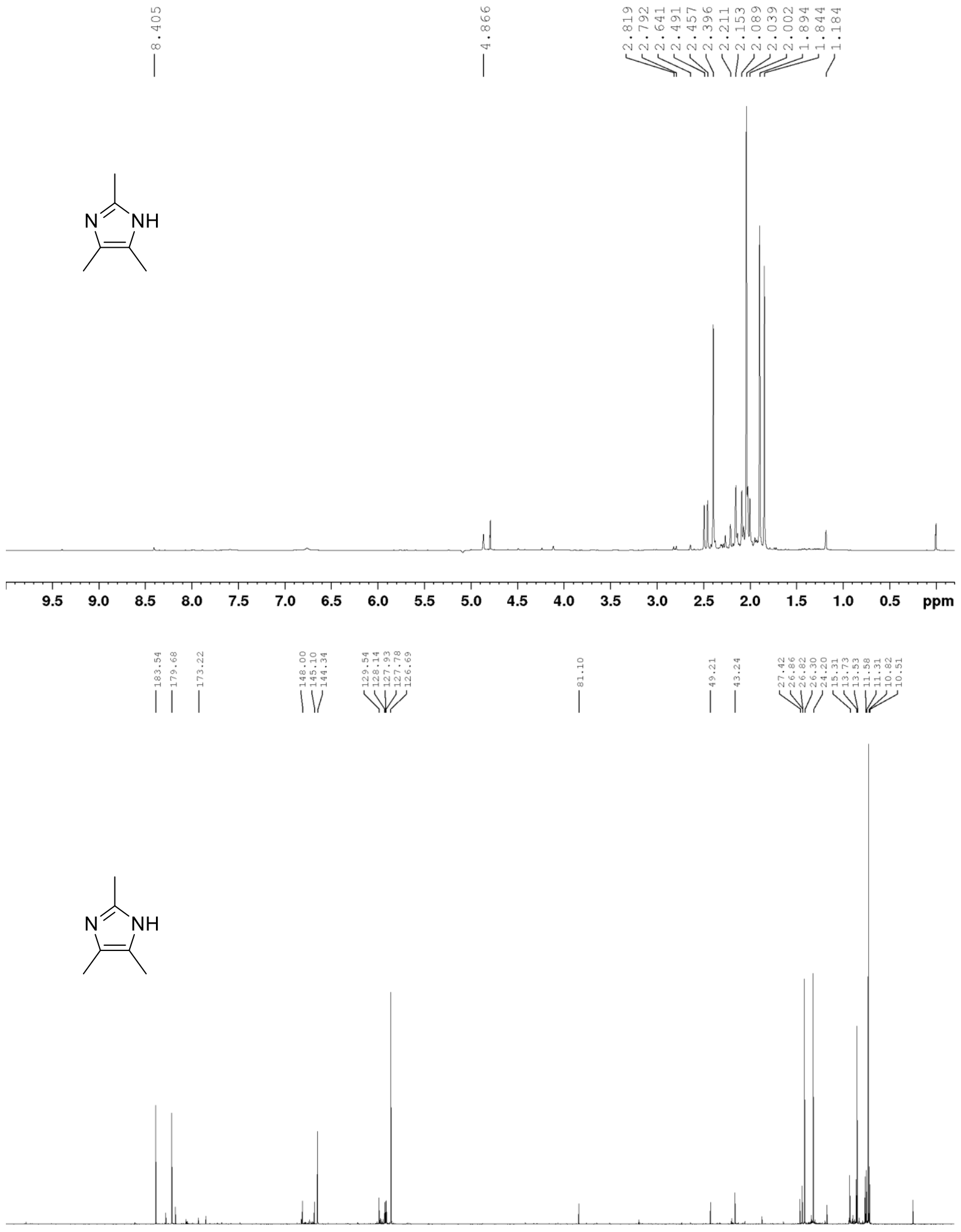

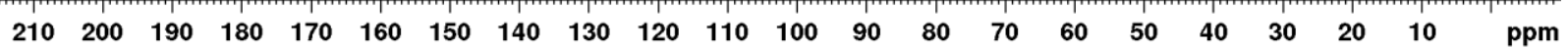


${ }^{1} \mathrm{H}$ and ${ }^{13} \mathrm{C}$ NMR of $1,2,4,5 \mathrm{MIm}$ after oxidative degradation experiment
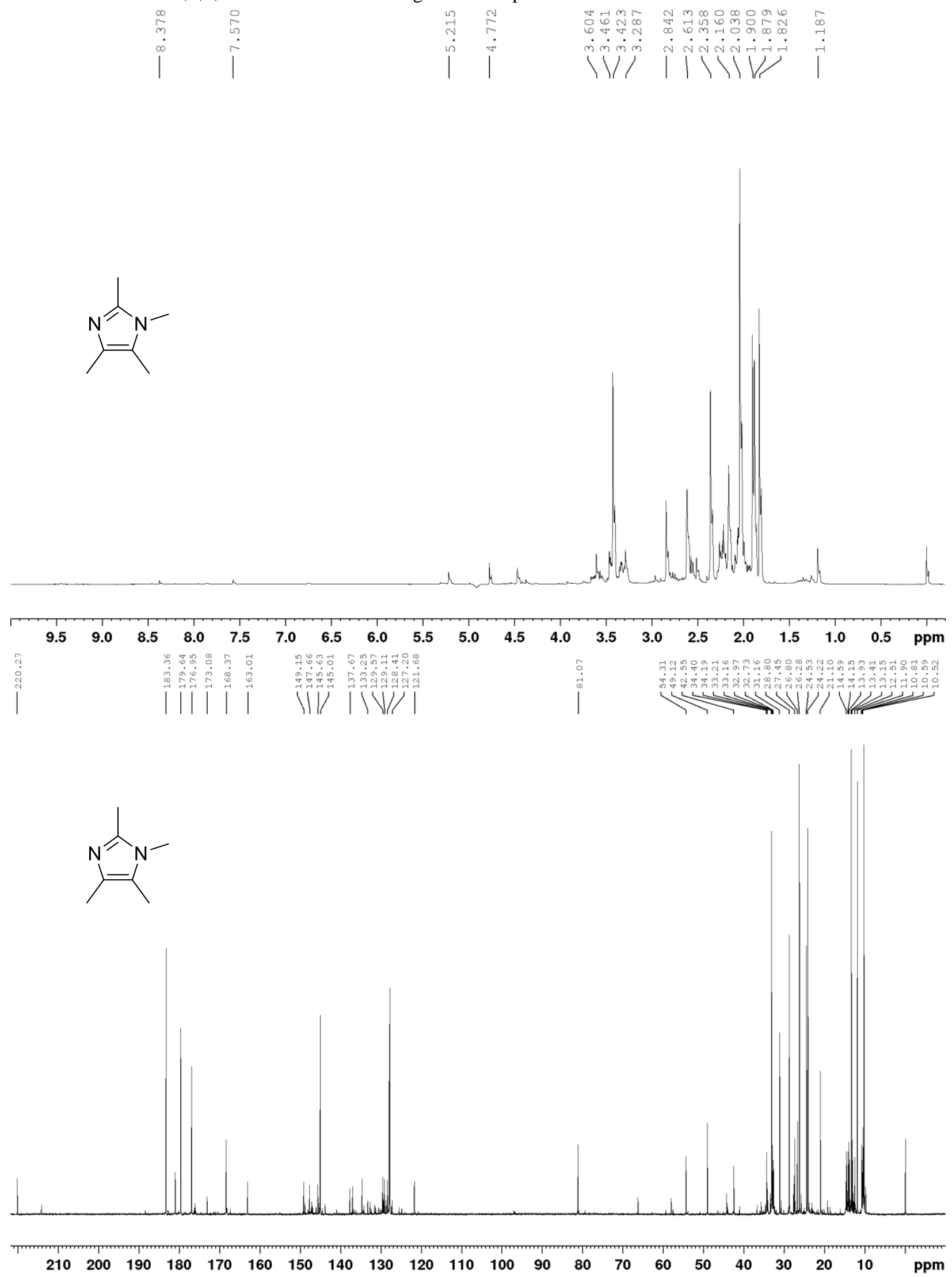